\title{
Hydrometeorological droughts in the Miño-Limia-Sil hydrographic demarcation (northwestern Iberian Peninsula): the role of atmospheric drivers
}

\author{
Rogert Sori $^{1,2}$, Marta Vázquez ${ }^{1,2,3}$, Milica Stojanovic ${ }^{2}$, Raquel Nieto ${ }^{1}$, Margarida L. R. Liberato ${ }^{2,3}$, and Luis Gimeno \\ ${ }^{1}$ Environmental Physics Laboratory (EPhysLab), CIM-UVigo, Universidade de Vigo, 32004 Ourense, Spain \\ ${ }^{2}$ Instituto Dom Luiz, Faculdade de Ciências, Universidade de Lisboa, 1749-016 Campo Grande, Portugal \\ ${ }^{3}$ Escola de Ciências e Tecnologia, Universidade de Trás-os-Montes e Alto Douro, 5001-801 Vila Real, Portugal
}

Correspondence: Rogert Sorí (rogert.sori@uvigo.es)

Received: 23 September 2019 - Discussion started: 25 September 2019

Revised: 16 May 2020 - Accepted: 30 May 2020 - Published: 26 June 2020

\begin{abstract}
Drought is one of the world's primary natural hazards because of its environmental, economic, and social impacts. Therefore, monitoring and prediction for small regions, countries, or whole continents are challenging. In this work, the meteorological droughts affecting the MiñoLimia-Sil hydrographic demarcation in the northwestern Iberian Peninsula during the period of 1980-2017 were identified. For this purpose and to assess the combined effects of temperature and precipitation on drought conditions, the 1-month standardized precipitation evapotranspiration index (SPEI1) was utilized. Some of the most severe episodes occurred during June 2016-January 2017, September 2011-March 2012, and December 2014-August 2015. An empirical-orthogonal-function analysis revealed that the spatial variability of the SPEI1 shows strong homogeneity in the region, and the drought phenomenon consequently behaves in the same way. Particular emphasis was given to investigating atmospheric circulation as a driver of different drought conditions. To this aim, a daily weather type classification based on the Lamb weather type (LWT) classification was utilized for the entire Iberian Peninsula. Results showed that atmospheric circulation from the southwest, west, and northwest are directly related to wet conditions in the MiñoLimia-Sil hydrographic demarcation during the entire hydrological year. Contrastingly, weather types imposing atmospheric circulation from the northeast, east, and southeast are best associated with dry conditions. Anomalies of the integrated vertical flow of humidity and their divergence for the onset, peak, and termination of the 10 most severe drought
\end{abstract}

episodes also confirmed these results. In this sense, the major atmospheric teleconnection patterns related to dry and wet conditions were the Arctic Oscillation, Scandinavian pattern, and North Atlantic Oscillation. Hydrological drought investigated through the standardized runoff index was closely related to dry and wet conditions revealed by the SPEI at shorter temporal scales (1-2 months), especially during the rainy months (December-April).

\section{Introduction}

Drought is one of the most dangerous natural phenomena in many regions worldwide, as it affects a wide range of environmental, economic, and social sectors (Wilhite, 2000; McMichael and Lindgren, 2011; Stanke et al., 2013; WMO and GWP, 2017; Liberato et al., 2017; Guerreiro et al., 2018). This phenomenon is usually considered to be a prolonged dry period in the natural hydrologic cycle that can occur anywhere in the world. It is initially caused by a lack of rainfall as well as by thermodynamic processes (e.g. turbulent fluxes and water phase transitions; Wehrli et al., 2018) induced by aerodynamics (wind speed), radiation forces (solar and long-wave), and thermal forces (high temperatures) (Vicente-Serrano et al., 2010; Seneviratne, 2012; WMO and GWP, 2016; Miralles et al., 2019). Drought propagation is also due to natural and human drivers through multiple feedbacks (Van Loon et al., 2016). The Iberian Peninsula (IP) in the Euro-Atlantic and Mediterranean regions is a drought- 
prone area (Páscoa et al., 2017) that was affected by severe droughts in 2004-2005 (García-Herrera et al., 2007), 20112012 (Trigo et al., 2013), and 2016-2017 (García-Herrera et al., 2019). Concerning the existence of the trends in droughts, Lloyd-Hughes and Saunders (2002) found a significant negative linear trend on the series of the Palmer Drought Severity Index (PDSI) over the period of 1901-1999 in the northwestern IP (hereafter NWIP). Higher atmospheric evaporative demand increased the severity of climatic droughts during the period of 1961-2011 in the IP, which contributed to a decrease in surface water resources (Vicente-Serrano et al., 2014). However, these authors also argued that drought variability has mainly been controlled by precipitation. Coll et al. (2017) reported that the rise in temperature was responsible for the greater drought severity and larger surface area affected in the IP from the 1980s to 2010 (with respect to the period of 1906-2010), as it led to an increase in atmospheric evaporative demand. A significant tendency towards dryness during 1975-2012 in the IP was also revealed by Páscoa et al. (2017). These authors showed that the northwestern region of the IP was particularly affected by these trends. Over a shorter study period (1974-2010), Gómez-Gesteira et al. (2011) found a significant increasing trend of $0.5^{\circ} \mathrm{C}$ per decade in air temperature in this same region and $0.24^{\circ} \mathrm{C}$ per decade in the sea surface temperatures of the adjacent Atlantic Ocean, but annual precipitation did not show any significant trend in the interior, which suggested a possible dominant role of temperature on the occurrence of drought in this region. Although the results described above agree with respect to the occurrence of a trend towards drier conditions in the IP during recent decades, the findings of Spinioni et al. (2017) reveal noticeable differences with respect to the trends and severity of droughts among the winters of 19502014 and 1981-2014 and the spring, summer, and autumn seasons of 1950-2015 and 1981-2015 in the IP. Overall, the high confidence level that global warming is likely to reach $1.5^{\circ} \mathrm{C}$ above preindustrial levels within a short period (between 2030 and 2052) if the current rate of increase continues is presently a serious concern (IPCC, 2018). In this sense, the IP is considered to be one of the most likely European regions to suffer from an increase in drought severity during the 21st century (Spinioni et al., 2018). However, Trenberth et al. (2014) argued that increased heating from global warming may not necessarily cause more droughts, but when they do occur, they would be expected to exhibit a rapid onset and greater intensity.

Drought processes involve interactions amongst ocean processes (ocean teleconnections), land-based processes (water balance and runoff), and several atmospheric processes (Spinioni et al., 2017). Therefore, multiple analyses have been used to investigate droughts and their impact on the availability of water resources in the IP. These include the implementation of circulation weather type (CWT) classifications (Cortesi et al., 2014; Ramos et al., 2014); identification of atmospheric blocking events (Sousa et al.,
2016); and assessments of climatic teleconnection patterns like the North Atlantic Oscillation (NAO; Muñoz-Díaz and Rodrigo, 2004; Trigo et al., 2004; deCastro et al., 2006a), which is considered to be a dominant mode of climate variability for Europe (Visbeck et al., 2001); the Arctic Oscillation (AO; deCastro et al., 2006a); the El Niño-Southern Oscillation (ENSO) (Vicente-Serrano, 2005); and the Scandinavian pattern (SCAND; deCastro et al., 2006a). The impacts of drought in the IP have been widely investigated. Droughts have been found to affect the productivity of rainfed crops (Peña-Gallardo et al., 2019) and forests (Gouveia et al., 2009; Barbeta and Peñuelas, 2016; Vidal-Macua et al., 2017; Peña-Gallardo et al., 2019) and have even resulted in human mortality in Galicia, northwestern Spain (Salvador et al., 2019). Terrestrial ecosystems often vary significantly in their responses to drought (Knapp et al., 2015). Moreover, the IP is characterized by different climate types, which vary from a humid Atlantic climate in the northwest and north to a semi-arid Mediterranean climate in the east and southeast (Parracho et al., 2016); it also features strong seasonal variability (Serrano et al., 1999). Therefore, regional-scale studies would have the advantage of better characterizing the phenomenon of drought and its impacts in this region, thereby supporting the reduction of drought vulnerability as well as drought-induced losses.

The NWIP is a hydrologically important region where water resources of the Miño-Sil and Limia River basins represent an important source of benefits for inhabitants of Galicia and the northern provinces of Portugal. Both basins make up the Miño-Limia-Sil hydrographic demarcation (MLSHD; Fig. 1), a region of shared environmental resources for Spain and Portugal. The water resources in the MLSHD are crucial to developing agriculture and livestock. Indeed, in the Spanish portion of the MLSHD, $73.2 \%$ of the total water demand is for agrarian use (Vargas and Paneque, 2019), principally irrigation (PH, 2014). The industrial use of water for energy production is mainly carried out through hydroelectric and thermal power plants, which has caused hydromorphological alterations in the primary river channels due to the construction of dams and dikes (deCastro et al., 2006b; PH, 2014). The hydroelectric power plants in the Spanish part of the MLSHD have a percentage of installed power that supposes a gross production of $5878.18 \mathrm{GWh}$ (average in the period of 2004-2013), which represents $44.88 \%$ of the total generated in the region (PH, 2014).

To the best of our knowledge, there are few published studies about drought considering the MLSHD as a whole. Ojeda et al. (2019) investigated the temporal evolution of agricultural and hydrological droughts in the major river basins of the IP during the period of 1980-2014 through modelling datasets. Considering the importance of the MLSHD as a hydrological unit, our main aim is to not only investigate the meteorological droughts which have affected the MLSHD using high-resolution gridded datasets but also to evaluate the role of atmospheric circulation and large- 


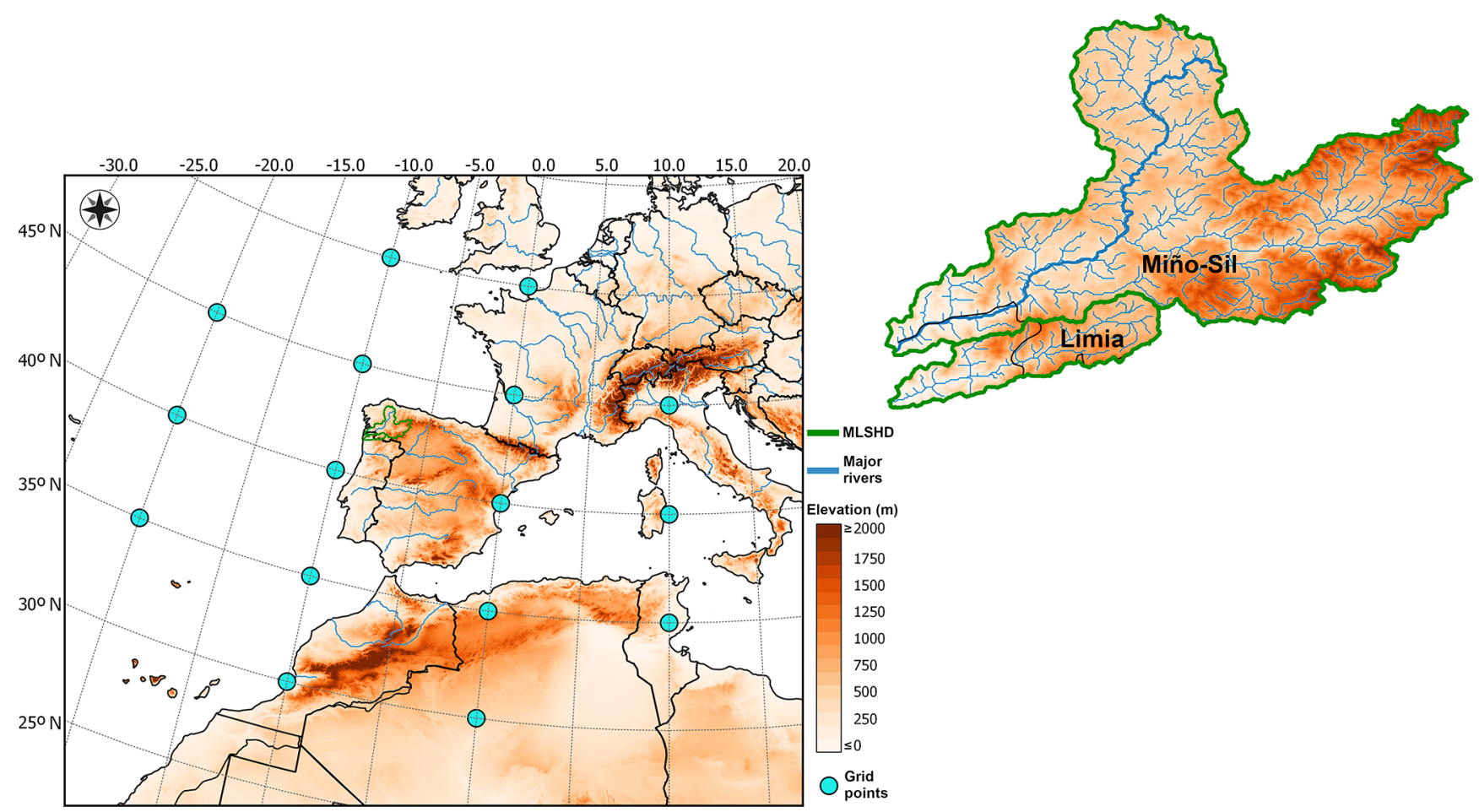

Figure 1. Geographic location and boundaries (green line) of the Miño-Sil and Limia River basins which conform to the Miño-Limia-Sil hydrographic demarcation (MLSHD). The rivers are represented by blue lines, and elevation is shaded in red (in metres above sea level) from the HydroSHEDS project (Hydrological data and maps based on SHuttle Elevation Derivatives at multiple Scales; Lehner et al., 2011). Light-blue circles denote the location of the 16 points used to retrieve daily mean sea level pressure (MSLP) values for the computation of the circulation weather types (CWTs).

scale teleconnection patterns in the occurrence and magnitude of droughts over a longer period (1980-2017). Russo et al. (2015) carried out a similar analysis for the entire IP, but their approach identified the seasonal conditions of the drought state and related them to the frequency of weather types during 1950-2012. In this study, we focus on meteorological droughts for explaining the primary cause of other types of droughts (e.g. agricultural, hydrological, and socioeconomic). These are normally associated with the reduction of the soil moisture content; low river flows; low water levels in rivers, lakes, and groundwater; and socioeconomic impacts due to water scarcity (WMO, 2012). Hydrological and agricultural droughts are primarily driven by meteorological droughts; therefore, their forecasts also heavily depend on weather forecasting. Identifying mechanisms that drive meteorological droughts and investigating drought characteristics is essential to improve forecasting methods and proactively monitor for early warnings, which contribute to efficient water management and the preservation of the ecosystems and socioeconomic stability. We expect that our results will contribute to increasing the hydroclimate knowledge of the MLSHD, support early-warning forecasting, and strengthen drought management plans.

\subsection{Study area}

The MLSHD extends from approximately 42 to $44^{\circ} \mathrm{N}$ and from 6.5 to $9^{\circ} \mathrm{W}$ and covers an area of approximately $20000 \mathrm{~km}^{2}$ in the NWIP (Fig. 1), including the territories of Galicia (Spain) and northern Portugal. There are $191 \mathrm{mu}-$ nicipalities, of which 181 belong to the Spanish territory and 10 to the Portuguese territory, with a total population of 1084636 people (as of 2015; Mora-Aliseda et al., 2015). It is designated as a "management unit", where the terrestrial area is composed of the Miño-Sil and Limia River basins and the transitional, subterranean, and coastal waters are associated with basins (PES, 2017). The MLSHD is characterized by the presence of a diverse landscape based on a complex relief structure and Atlantic bioclimatic characteristics. The Miño-Sil basins have a pronounced mountainous character with an average elevation of $\sim 683 \mathrm{~m}$ a.s.l. (above sea level; UN, 2011), while the Lima River basin is at $\sim 447 \mathrm{~m}$ a.s.l. (CA, 2020). The rugged coastlines, valleys, and mountains present a wide variety of landscapes in a unique combination compared to those of the surrounding peninsular territories. In terms of the annual mean flow, the Miño-Sil River basin is the fourth largest basin in the IP and because of that is important for hydropower generation (Lorenzo-Lacruz et al., 2013; Añel et al., 2014). 

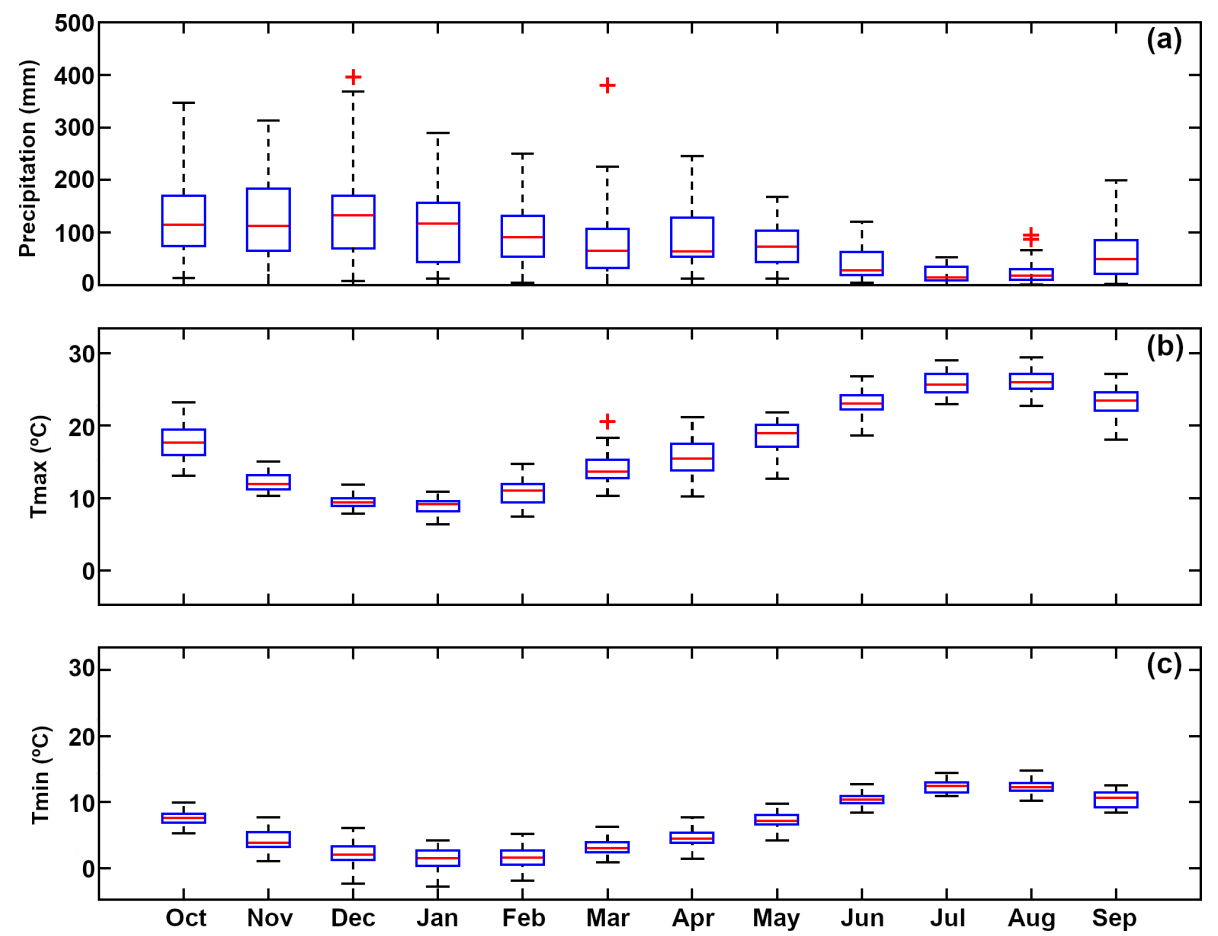

Figure 2. The annual cycle for the hydrological year spanning October of year $n$ to September of year $n+1$, for the period of 1980-2017, for (a) monthly mean precipitation, (b) maximum temperature, and (c) minimum temperature in the MLSHD, using the E-OBS gridded dataset. Boxes delineate the median (red line), upper, and lower quartiles, with the whiskers representing the lowest and highest monthly value still within 1.5 of the interquartile range. Outliers, i.e. values beyond the ends of the whiskers, are denoted by a + symbol.

Its climate is characterized by mild winters, cool summers, humid air, abundant cloudiness, and frequent rainfall. A box plot of the monthly mean precipitation, maximum temperature, and minimum temperature from the E-OBS gridded dataset (European gridded observational dataset; Cornes et al., 2018) reveals the hydrological year (October of year $n$ to September of year $n+1)$ in the MLSHD (Fig. 2). The precipitation presents a high temporal variability across the year. According to the values of the median, the rainiest months are December and January, while the less rainy months are July and August (Fig. 2a). As expected, the greatest scattering for precipitation occurs during the autumn and winter months. Both the Miño and the Sil are remarkably regulated rivers, although they have a maximum flow in winter (January and February) and a minimum in summer (August and September; Añel et al., 2014). During winter, the large-scale circulation is mainly driven by the position and intensity of the Iceland Low, and western Iberia is affected by westerly winds that bring humid air and generate precipitation (Trigo et al., 2004). The movement of the sub-tropical anticyclone to the south leaves the region open to the influence of the frontal systems from the west, which are responsible for most of the precipitation. Synoptic-scale baroclinic perturbations from the Atlantic Ocean are responsible for most of the precipitation between October and May (deCastro et al., 2006a). Indeed, this period of months can be considered as the rainy season. Summer is predominantly influenced by high pressures, which determine air subsidence and consequently atmospheric stability (Lorenzo et al., 2008). The annual cycle of maximum and minimum temperature reveals an opposite cycle to that of precipitation (Fig. $2 \mathrm{~b}$ and c). According to the quartile distribution of monthly mean temperatures values, the coldest months are December, January, and February; in these months, the extreme values of the average minimum temperature for the MLSHD has dropped to values below $0^{\circ} \mathrm{C}$. Finally, according to the interquartile range distribution of the maximum average temperature and middle values of 25.6 and $25.9^{\circ} \mathrm{C}$, July and August, respectively, are the hottest months.

\section{Material and methods}

\subsection{Datasets}

Monthly gridded data of precipitation, maximum temperature, and minimum temperature were obtained from daily values of the E-OBS v.18e gridded dataset (Cornes et al., 2018) with a longitudinal and latitudinal resolution of $0.1^{\circ}$ for the period of 1980-2017. Owing to their high resolution, these datasets have been utilized to investigate extreme precipitation (Tabari and Willems, 2018) and drought events in Europe (Manning et al., 2019). However, the sparse distribu- 
tion network in some European regions has led to an oversmoothing of precipitation intensities (Hofstra et al., 2009, 2010; Sunyer et al., 2013; Herrera et al., 2019). A comparison between daily precipitation and temperatures from standard and ensemble E-OBS datasets with the observational gridded dataset Iberia01 performed by Herrera et al. (2019) revealed that the main differences of temperatures occurred in the south, around the Guadalquivir and Guadiana basins, and respect the precipitation the high biases in the central IP and the Mediterranean regions. In addition to the high resolution, these datasets were chosen for this study because they provide both precipitation and temperature fields necessary for the computation of the standardized precipitation evapotranspiration index (SPEI), thus minimizing errors that could arise due to the mixing of different datasets.

The period of 1980-2017 was set for all the analyses in this study taking into account the simultaneous availability of data and a period of more than 30 years. These datasets were utilized to compute the SPEI in the MLSHD. For the CWT computation, daily values of sea level pressure (SLP) from the ERA-Interim (ECMWF Reanalysis) reanalysis datasets (Dee et al., 2001) with a resolution of $1^{\circ}$, based on the 16 grid points shown in Fig. 1, were utilized. The eastward-northward vertically integrated moisture flux from ERA-Interim was utilized to compute the anomalies of vertical integral moisture flux (VIMF) and its divergence anomalies. Monthly values of runoff with a resolution of $\sim 4 \mathrm{~km}$ were freely downloaded from the portal TerraClimate (available at http://www.climatologylab. org/terraclimate.html, last access: 30 March 2020; Abatzoglou et al., 2018). TerraClimate uses climatically aided interpolation, combining high-spatial-resolution climatological normals from the WorldClim dataset with coarser-spatialresolution and time-varying data from CRU TS4.0 (Climate Research Unit Time Series) and the Japanese 55-year Reanalysis (JRA55).

To identify the influence of short and large-scale modes of climate variability on the hydroclimate of the study region, various datasets of teleconnection patterns were used. These were the bivariate ENSO time series (BEST; available at https://www.esrl.noaa.gov/psd/people/cathy.smith/best/, last access: 30 March 2020; Smith and Sardeshmukh, 2000), the Western Mediterranean Oscillation (WeMO; available at https://crudata.uea.ac.uk/cru/data/moi/, last access: 30 March 2020), East Atlantic pattern (EA), NAO, AO, and SCAND (available at https://www.cpc.ncep.noaa.gov/ data/teledoc/telecontents.shtml, last access: 30 March 2020). The BEST index time series is based on the combination of the atmospheric component of the ENSO phenomenon (the Southern Oscillation Index; SOI) and an oceanic component (average Niño 3.4 sea surface temperature). The WeMO index (WeMOi) is based on the difference between the standardized atmospheric pressure recorded at Padua $\left(45.40^{\circ} \mathrm{N}, 11.48^{\circ} \mathrm{E}\right)$ in northern Italy and San Fernando Cádiz $\left(36.28^{\circ} \mathrm{N}, 6.12^{\circ} \mathrm{W}\right)$ in southwestern Spain. To ob- tain the teleconnection indices of the Northern Hemisphere (EA, NAO, AO, and SCAND), the Climate Prediction Center (CPC) applies a rotated principal component analysis (RPCA) proposed by Barnston and Livezey (1987), using the monthly mean standardized $500 \mathrm{mb}$ height anomalies from the NCEP/NCAR Reanalysis (National Centers for Environmental Prediction; National Center for Atmospheric Research; Climate Data Assimilation System - CDAS) in the analysis region of $20-90^{\circ} \mathrm{N}$.

\subsection{Drought identification: the standardized precipitation evapotranspiration index (SPEI)}

Different types of droughts make it difficult to conceive a universal drought index. Therefore, there are many indices and different criteria to identify and investigate different types of droughts (Svodoba and Fuchs, 2016; WMO and GWP, 2016). However, ultimately drought is caused by an imbalance between water supply and demand. Therefore, the SPEI (Vicente-Serrano et al., 2010) was chosen to identify dry conditions in the MLSHD during the period of 1980-2017. This index is based on the same methodology of the standardized precipitation index (SPI; McKee et al., 1993). However, as an advantage over common precipitation-based drought indices (e.g. the SPI), the SPEI considers the effects of temperature through the reference parameter of evapotranspiration $\left(\mathrm{Et}_{0}\right)$ in the climatic water balance represented in Eq. (1):

$D=\left(P-\mathrm{Et}_{0}\right)$,

where $D$ is the water balance over a given period of time, $P$ is the precipitation that represents water availability, and $\mathrm{Et}_{0}$ represents the atmospheric water demand. Therefore, the SPEI combines the changes the atmospheric evaporative demand with the multiscalar nature of the SPI (Beguería et al., 2014), which allows for the assessment of the response of different ecological, hydrological, and agricultural systems to drought (Vicente-Serrano et al., 2012). In consequence, it has been applied to a large variety of ecosystems across the world for identifying dry and wet conditions and evaluating drought recurrence (Potop et al., 2013; Vicente-Serrano et al., 2016; Salah et al., 2018; Sordo-Ward et al., 2017; Wang et al., 2018). It was also chosen for this study because the results of Vicente-Serrano et al. (2014) described how drought severity has increased in the past 6 decades (1954-2014) in natural, regulated, and highly regulated basins of the IP as a consequence of greater atmospheric evaporative demand resulting from temperature rise.

$\mathrm{Et}_{0}$ values are a climatic parameter that expresses the evaporating power of the atmosphere at a specific location and time of the year (Allen et al., 1998). In the absence of meteorological data required for applying the Penman-Monteith equation, which is recommended by the Food and Agriculture Organization (FAO) of the United Nations in the FAO bulletin 56 (Allen et al., 1998), we used the method proposed 
by Hargreaves and Samani (1985). It is based on temperature data to estimate the $\mathrm{Et}_{0}$ value according to Eq. (2):

$\mathrm{Et}_{0}=0.0023 \cdot \mathrm{Ra} \cdot\left(\sqrt{T_{x}-T_{n}}\right) \cdot\left(T_{m}+17.8\right)$,

where 0.0023 is a constant value; $\mathrm{Ra}$ is the extra-terrestrial radiation (derived from the latitude and the month of the year); and $T_{x}, T_{n}$, and $T_{m}$ are the maximum, minimum, and mean temperature, respectively. By this method, we do not consider relative humidity and wind speed to also be important factors for determining the vapour density above the soil surface and the aerodynamic resistance for vapour transport, which permit more realistic $\mathrm{Et}_{0}$ values and consequently better drought assessment (Bittelli et al., 2008; Vicente-Serrano et al., 2010; WMO, 2012; Davarzani et al., 2014). However, even though the Penman-Monteith equation offers a more accurate estimation of reference $\mathrm{Et}_{0}$ values than the Hargreaves formula (López-Moreno et al., 2009; Tomas-Burguera et al., 2017), results of Vicente-Serrano et al. (2014) showed that $\mathrm{Et}_{0}$ values in Spain estimated by the Hargreaves-Samani method for the period of 1961-2011 had the closest agreement with the $\mathrm{Et}_{0}$ values obtained by the Penman-Monteith method in terms of temporal evolution and magnitude with respect to over 11 other methods. These authors also found high correlations between an $\mathrm{Et}_{0}$ value obtained by both methods in the NWIP.

The resultant $D$ values in Eq. (1) were aggregated at different timescales, following the same procedure as the SPI. According to Vicente-Serrano et al. (2010), Beguería et al. (2014), and Vicente-Serrano and Beguería (2016), the developers of the index, to calculate the SPEI at different timescales, the most suitable statistical distribution to model the $D$ series is the log-logistic distribution, which is given by Eq. (3):

$F(D)=\left[1+\left(\frac{\alpha}{D-\gamma}\right)^{\beta}\right]^{-1}$,

where $\alpha, \beta$, and $\gamma$ represent the scale, shape, and location parameters that are estimated from the sample $D$. Finally, the SPEI is obtained as the standardized values of $F(D)$. Previous studies have been also used the log-logistic distribution to obtain the SPEI series for the IP (e.g. Russo et al., 2015; Páscoa et al., 2017; Coll et al., 2017; Ojeda et al., 2019). For our study region, it is possible that the $D$ values demonstrate a better fit to a different probabilistic distribution; however, this can also occur for different accumulation periods of $D$ (Monish and Rehana, 2020). The use of different probabilistic distributions to fit the $D$ series may primarily affect the tail of each distribution and the extreme SPEI values (Vicente-Serrano et al., 2010; VicenteSerrano and Beguería, 2016), e.g. the $[-2.33,2.33]$ bounds (one event in 100 cases). For these reasons, we preferred to use the distribution suggested by the authors of the index to calculate the SPEI on a timescale of 1 to 24 months.
Table 1. SPEI classification according to Agnew (2000).

\begin{tabular}{lcl}
\hline SPEI & Probability & Category \\
\hline$>1.65$ & 0.05 & Extremely humid \\
$>1.28$ & 0.10 & Severely humid \\
$>0.84$ & 0.20 & Moderately humid \\
$>-0.84$ and $<0.84$ & 0.60 & Normal \\
$<-0.84$ & 0.20 & Moderately dry \\
$<-1.28$ & 0.10 & Severely dry \\
$<-1.65$ & 0.05 & Extremely dry \\
\hline
\end{tabular}

For the calculation of the SPEI, the R package available at http://cran.r-project.org/web/packages/SPEI (last access: 19 September 2019) is utilized. It includes all the recommendations proposed by Beguería et al. (2014).

We avoided considering that any precipitation below the mean constitutes a drought. Therefore, the classification of drought categories for SPI values proposed by Agnew (2000) (Table 1) was utilized in this study. Other authors have also employed this classification for investigating drought in the IP (e.g. Vicente-Serrano, 2007; Páscoa et al., 2017). This classification, despite being pre-established, was built by probability classes rather than magnitudes of the SPI and is, therefore, a more rational approach, with a noticeable effect at the demarcation of mild and moderate droughts (Agnew, 2000). We focus on the SPEI at a 1-month temporal scale (hereafter SPEI1) to identify meteorological drought episodes. At this timescale the SPEI and the SPI can reflect short-term conditions, and consequently, its application can be closely related to meteorological types of droughts (WMO, 2012). A drought episode occurs every time the SPEI1 is continuously negative and reaches the value of -0.84 or less. The onset of an episode is the month in which the episode begins; the peak is the month in which the episodes reach the highest negative value of the SPEI1; and the end is the last month that the SPEI1 is negative. The threshold of -0.84 corresponds to $20 \%$ probabilities, whereby a drought is expected to occur once in 5 years, which reduces the incidence of mild meteorological droughts. The duration is calculated as the sum of the consecutive number of months with negative SPEI values since the onset of the episode, and the severity is calculated as the sum of all SPEI values (in absolute values) during the episode.

To identify the principal patterns of drought variability in the MLSHD, an empirical-orthogonal-function (EOF) analysis (Preisendorfer and Mobley, 1988; von Storch, 1995) was utilized. The EOF analysis is not based on physical principles; rather, the technique aims to decompose observed datasets into two components that capture most of the observed variance in space (eigenvalues) and time (eigenvectors). It makes easier to study the principal modes of variability of the SPEI1 time series for every grid point of the MLSHD. The percentage of the total variance explained by 
each eigenvalue is able to explain most of the spatial drought variance. This method has been extensively used to investigate droughts at global (e.g. Dai, 2011) and regional (Wang et al., 2017, 2019) scales.

Trend analysis using the Mann-Kendall test (Mann, 1945; Kendall, 1975) of pre-whitened time series data in the presence of serial correlation using the approach of von Storch (1995) was performed. This approach ensures the avoidance of possible autocorrelation of the series. The null hypothesis $\left(H_{0}\right)$ is that the data come from a population with independent realizations and are identically distributed, while the alternative hypothesis $\left(H_{\mathrm{a}}\right)$, is that the data follow a monotonic trend. With a significance level of 0.05 , the null hypothesis of no trend is rejected if the $|Z|$ score is greater than the critical value 1.96. Sen's slope (Sen, 1968) was used to determine the magnitude of trend increasing or decreasing in the period of study. The combination of both methods has often been used to analyse the trend change of hydrometeorological time series data such as precipitation, runoff, and the drought index. For this analysis, the R package "modifiedmk" (Patakamuri and O’Brien, 2019) was used.

\subsection{The standardized runoff index (SRI)}

The SRI was applied to investigate the occurrence and temporal evolution of hydrological droughts in the MLSHD. To compute this index, we used the same approach employed by McKee et al. (1993) to compute the SPI. According to these authors, the procedure can be applied to other variables relevant to drought, e.g. streamflow or reservoir contents. Thus, the gamma distribution was used for fitting monthly runoff data for accumulation periods up to 6 months.

\subsection{Weather type classification methodology}

Synoptic systems are linked to the dominant climate in any region of the planet. These systems represent the general circulation of the atmosphere through different configurations of variables. For this reason, a semi-objective classification scheme based on the methodology adopted by Trigo and DaCamara (2000) from the Jenkinson and Collison (1977) and Jones et al. (1993) circulation schemes is applied to obtain the dominant circulation weather types (CWTs) over the IP. The method uses daily mean sea level pressure (MSLP) values obtained from the ERA-Interim reanalysis for the period of 1980-2017 on 16 different points over the IP and surrounding regions (light-blue circles are shown in Fig. 1) to build a set of indices associated with the direction and vorticity of the geostrophic flow. These are the total shear vorticity $(Z)$, southerly shear vorticity $\left(Z_{S}\right)$, westerly shear vorticity $\left(Z_{\mathrm{W}}\right)$, total flow $(F)$, southerly flow $\left(S_{\mathrm{F}}\right)$, and westerly flow $\left(W_{\mathrm{F}}\right)$. The area used to compute CWTs was the same as that used by Ramos et al. (2014); it extended from $20^{\circ} \mathrm{W}$ to $10^{\circ} \mathrm{E}$ longitudes and from 30 to $50^{\circ} \mathrm{N}$ latitudes. The regional indices were computed as follows; Eqs. (4) to (9) were calculated according to the procedure described in Ramos et al. (2014) and Trigo and DaCamara (2000).

$$
\begin{aligned}
S_{\mathrm{F}} & =1.305\left[0.25\left(p_{5}+2 \times p_{9}+p_{13}\right)\right. \\
& \left.-0.25\left(p_{4}+2 \times p_{8}+p_{12}\right)\right] \\
W_{\mathrm{F}} & =\left[0.5\left(p_{12}+p_{13}\right)-0.5\left(p_{4}+p_{5}\right)\right] \\
Z_{\mathrm{S}} & =0.85 \times\left[0.25\left(p_{6}+2 \times p_{10}+p_{14}\right)\right. \\
& -0.25\left(p_{5}+2 \times p_{9}+p_{13}\right) \\
& -0.25 \times\left(p_{4}+2 \times p_{8}+p_{12}\right) \\
& \left.+0.25\left(p_{3}+2 \times p_{7}+p_{11}\right)\right] \\
Z_{\mathrm{W}} & =1.12 \times\left[0.5 \times\left(p_{15}+p_{16}\right)-0.5 \times\left(p_{8}+p_{9}\right)\right] \\
& -0.91 \times\left[0.5 \times\left(p_{8}+p_{9}\right)-0.5 \times\left(p_{1}+p_{2}\right)\right] \\
F= & \left(S_{\mathrm{F}}^{2}+W_{\mathrm{F}}^{2}\right) \\
Z= & Z_{\mathrm{S}}+Z_{\mathrm{W}}
\end{aligned}
$$

Following this approach, 26 CWTs were initially identified (10 pure, 8 anticyclonic hybrids, and 8 cyclonic hybrids). The 16 points designated $p_{x}$ ( $x$ going from 1 to 16 according to the number of the point represented in Fig. 1) were taken into account in this computation. Purely directional CWTs northeastern (NE), eastern (E), southeastern (SE), northwestern $(\mathrm{NW})$, western $(\mathrm{W})$, southwestern $(\mathrm{SW})$, north $(\mathrm{N})$, and south (S) - were those showing $|Z|<F$ with the direction defined by $\tan -1\left(W_{\mathrm{F}} / S_{\mathrm{F}}\right)\left(180^{\circ}\right.$ was added if $W_{\mathrm{F}}$ was positive). If $|Z|>2 F$, then the circulation would be considered cyclonic (C) (if $Z>0$ ) or anticyclonic (A) (if $Z<0$ ). As not all the circulation patterns could be associated with a pure (directional, cyclonic, or anticyclonic) type, 16 hybrid circulations were defined as a combination of $\mathrm{A}$ and $\mathrm{C}$ circulations with directional CWTs. In this case, it is $F<|Z|<2 F$. Following Trigo and DaCamara (2000) in the frequency computation, the 26 CWTs were regrouped in the 10 pure circulations. Thus, each of the 16 hybrid types counted equally as a half occurrence to each of their corresponding purely directional and cyclonic or anticyclonic types (e.g. one case of CNW was included as 0.5 in $\mathrm{C}$ and 0.5 in NW). This same methodology but with a different source of mean sea level pressure datasets and lower resolution has been previously applied to investigate the relationships between atmospheric circulation and precipitation variability (e.g. Cortesi et al., 2014; Ramos et al., 2014) or drought conditions in the IP (e.g. Russo et al., 2015).

\subsection{Weather type classification methodology}

Wavelet coherence (WC) analysis was used to identify which frequency bands within two time series were co-varying (Torrence and Webster, 1999). This definition is similar to that of a traditional cross correlation, and the WC was considered as a localized correlation coefficient in timefrequency space (Torrence and Compo, 1998; Grinsted et al., 2004). For this assessment, the SPEI1 as well as the 6-month 
temporal-scale series of teleconnection patterns, namely the BEST, WeMO, NAO, AO, EA, and SCAND patterns, were utilized by initially applying Eq. (10), as follows:

$$
R_{n}^{2}(S)=\frac{\left|S\left(s^{-1} W_{n}^{X Y}(s)\right)\right|^{2}}{S\left(s^{-1}\left|W_{n}^{X}(s)\right|^{2}\right) \cdot S\left(s^{-1}\left|W_{n}^{Y}(s)\right|^{2}\right)}
$$

where $S$ is a smoothing operator and the variable $X Y$ is the two series. The WC ranged from 0 to 1 ; if the value was closer to 1 , then the correlation between the two series was higher. The cross-wavelet coherence analysis was performed using the "wtc" function through the "biwavelet" R package (https://CRAN.R-project.org/package=biwavelet, last access: 30 November 2019), and the WC 5\% significance level was determined using 1000 randomizations of Monte Carlo-generated noise. An advantage of the WC over the classical cross-correlation analysis is that the phase relationship is calculated such that the degree to which two time series are positively or negatively related can be measured as both a function of time and period (Schulte et al., 2016).

\section{Results and discussion}

\subsection{Drought conditions}

The NWIP is a homogeneous region in terms of the total precipitation variance over the IP (Rodríguez-Puebla et al., 1998; Muñoz-Díaz and Rodrigo, 2004) and consequently, also in terms of the influence of droughts (Russo et al., 2015). Figure 3 illustrates the temporal evolution of moderate, severely, and extremely dry conditions (according to the classification shown in Table 1) through the SPEI at a temporal scale of 1 to 24 months. As observed, dry conditions revealed by the short-term SPEI were more frequent and propagated at larger SPEI temporal scales. This shows a lagging and lengthening effect in the drought signal, from meteorological to hydrological droughts (Wang et al., 2016; Gu et al., 2020). A visual analysis confirms that after 2004 the MLSHD has been more frequently affected by severe droughts.

In order to investigate meteorological droughts in the MLSHD, an EOF analysis was performed with the gridded values of the SPEI1. The results in Fig. 4 reveal the spatial characteristics of the first three leading EOF modes, which explain $97.8 \%$ of the total spatial variability of the SPEI 1 in the MLSHD and the corresponding principal components (PCs). Because the spatial patterns of the remaining EOFs explain very low percentages, they are not shown. In particular, the EOF1 is characterized by entirely negative values, indicating that dry or wet conditions in the MLSHD manifest themselves homogeneously throughout its entire extension in a great percentage (93\%). The spatial coefficients of the EOF2 separate the eastern highlands from the north and west of the MLSHD, while the EOF3 reveals the north-south spatial differences. However, both explain just $2.6 \%$ and $2.2 \%$,
Table 2. Trend analysis according to Mann-Kendall (MK) tests of prewhitened time series and Sen's slope for the 1-month SPEI series and the number of episodes that start per year, their duration, and their severity. Statistically significant trends at $(p<0.05)$ and $Z$ scores are marked with an asterisk. Period of 1980-2017.

\begin{tabular}{lrrl}
\hline & $Z$ & Slope & Units \\
\hline SPEI1 & -1.98 & $-0.0007^{*}$ & $Z$ unit per year \\
Number of episodes & 0.40 & 0.0030 & Episodes per year \\
Duration & 1.66 & 0.0200 & Months per year \\
Severity & 1.97 & $0.0300^{*}$ & $Z$ unit per year \\
\hline
\end{tabular}

respectively. The PC1 exhibits less temporal variability than the $\mathrm{PC} 2$ and $\mathrm{PC} 3$, and none of the three presents statistically significant trends.

Figure 5a shows the temporal evolution of the SPEI1 computed for the MLSHD during 1980-2017. Drought conditions are observed in periods such as 1989-1992, 2004-2007, and 2015-2017, in agreement with results obtained by other authors for the NWIP through different indices (e.g. GarcíaHerrera et al., 2007; Andrade and Belo-Pereira, 2015; Spinioni et al., 2016; Ojeda et al., 2019). At this timescale, the negative values of the SPEI were primarily related to meteorological drought, which was unable to diagnose the agricultural, hydrological, and socioeconomic types of drought that are typically associated with the SPEI at greater temporal scales (WMO, 2012). However, meteorological droughts can be perceived as the initial cause of further types of droughts, since these are triggered in this case by the deficit of precipitation combined with high temperatures and significant $\mathrm{Et}_{0}$ values. The identification of meteorological drought episodes affecting the IP has been a topic of research during recent years (e.g. Lana et al., 2006; Lorenzo-Lacruz et al., 2013; Páscoa et al., 2017; González-Hidalgo et al., 2018). A drought episode was considered to occur every time the SPEI1 was continuously negative and reached the value of -0.84 or less; this threshold was identified by the black dashed line in Fig. 5a. The onset, termination, and duration of these episodes are shown in Fig. 5b.

A tendency analysis for our period of the study reveals a small negative trend in the series of the SPEI1 (statistically significant), an increase in the number and duration of the episodes (statistically non-significant), and a small increase in the severity of these episodes (statistically significant) (Table 2). Vicente-Serrano et al. (2011) also found that the mean duration of drought episodes in the NWIP increased by approximately 1 month in the last 30 years of 1930-2006 (difference statistically non-significant) as a consequence of the increase in a potential $\mathrm{Et}_{0}$ value.

Extreme drought events can disrupt food production systems and thus be a significant natural trigger for famine (Wilhite, 2000), and for the MLSHD they can directly affect hydroelectric production. The top 10 driest episodes in the period under this study according to their severity are shown in 


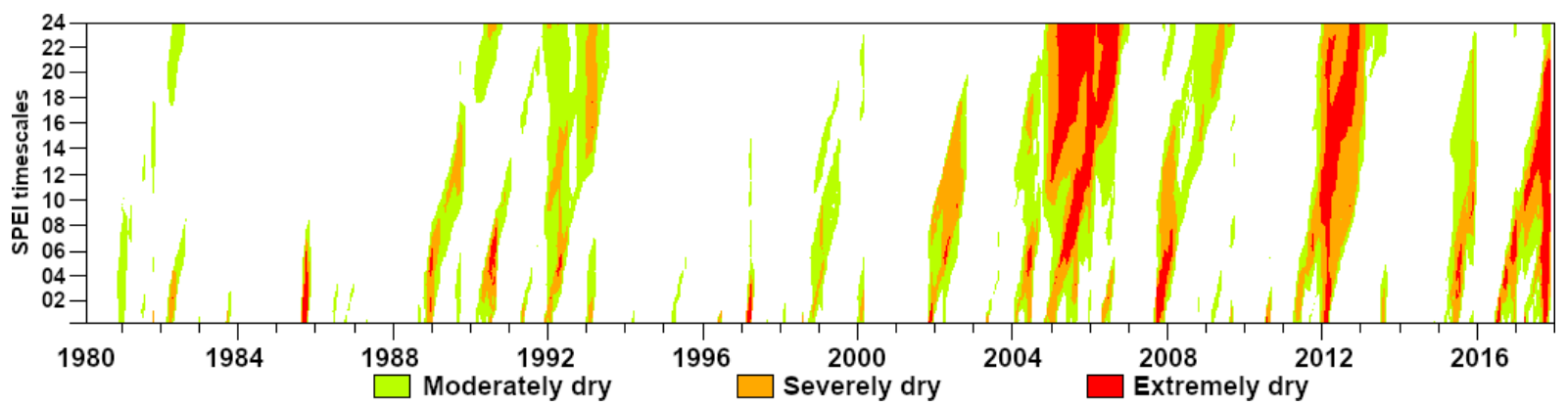

Figure 3. Temporal evolution of moderately, severely, and extremely dry conditions in the MLSHD according to the SPEI at a temporal scale of 1 to 24 months and the classification shown in Table 1. Period of 1980-2017.
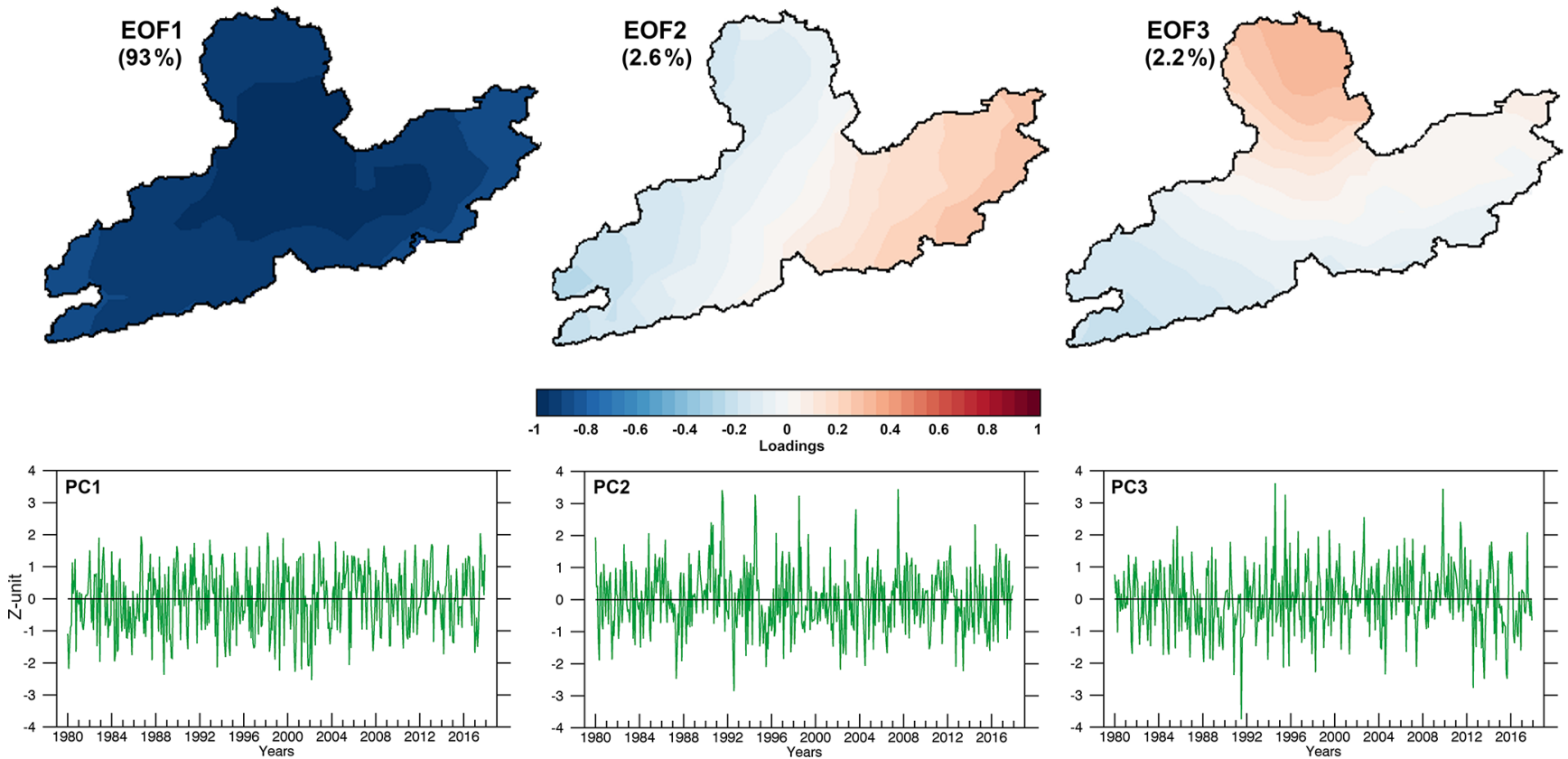

Figure 4. The first three leading EOF modes of the SPEI1 for the MLSHD. Period of 1980-2017. The numbers between parentheses correspond to the amount of variance explained by each EOF.

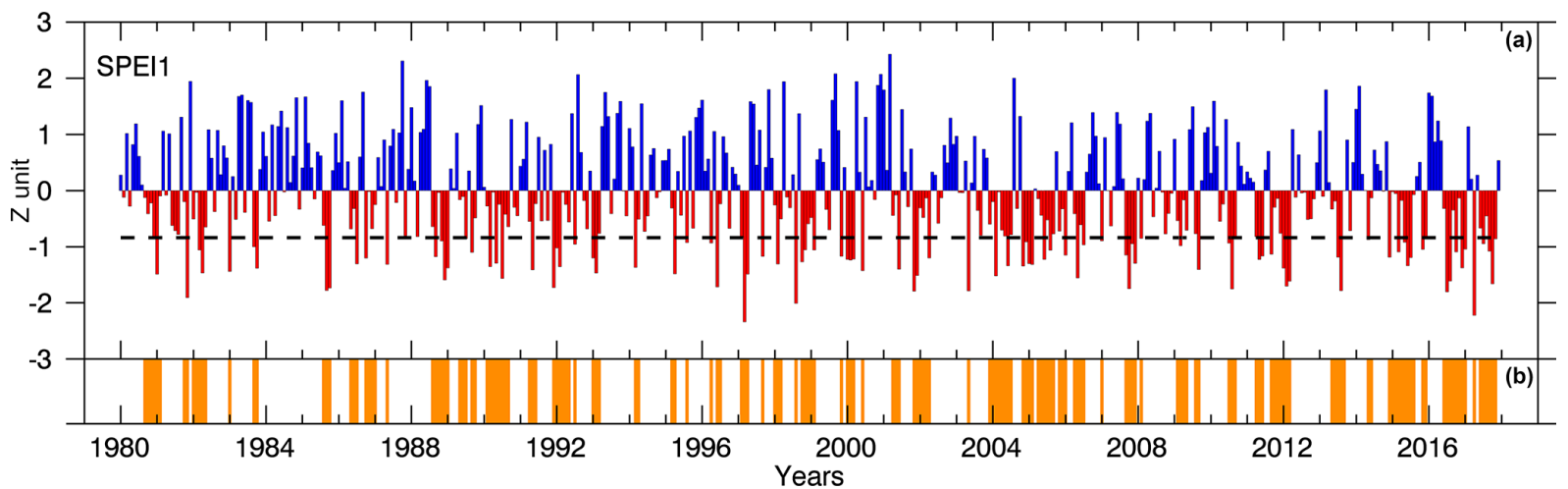

Figure 5. Wet (blue bars) and dry (red bars) conditions in the MLSHD according to the (a) SPEI1 and (b) dry episodes (orange bars) during 1980-2017. 

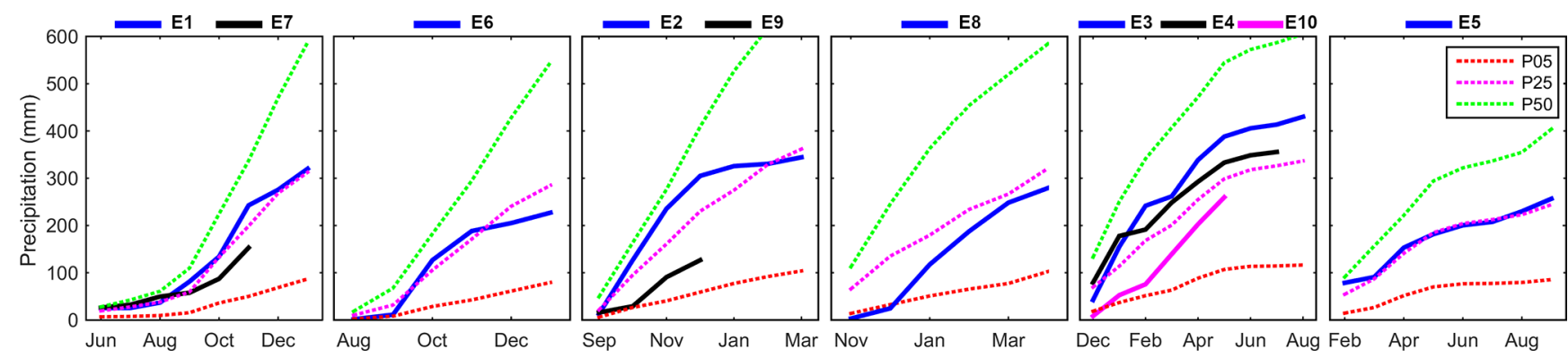

Figure 6. Accumulated precipitation during each drought episode listed in Table 3 (solid lines) and the monthly accumulated percentiles 5 (P05), 25 (P25), and 50 (P50) of precipitation (discontinued lines) while considering the whole study period (1980-2017).

Table 3. The 10 most severe drought episodes that affected the MLSHD from 1980 to 2017 arranged based on their severity from highest to lowest. The onset (first month of the episode), peak (lowest SPEI1 value during the episode), termination (last month of the episode), and duration (number of months from the onset to the termination) are shown.

\begin{tabular}{llllccc}
\hline Episode & Onset & Peak & End & $\begin{array}{c}\text { Peak } \\
\text { value }\end{array}$ & $\begin{array}{c}\text { Duration } \\
\text { (months) }\end{array}$ & Severity \\
\hline E1 & Jun 2016 & Jul 2016 & Jan 2017 & -1.80 & 8 & 7.7 \\
E2 & Sep 2011 & Feb 2012 & Mar 2012 & -1.70 & 7 & 7.0 \\
E3 & Dec 2014 & Jun 2015 & Aug 2015 & -1.34 & 9 & 6.1 \\
E4 & Dec 2003 & Feb 2004 & Jul 2004 & -1.52 & 8 & 6.0 \\
E5 & Feb 1990 & Jul 1990 & Sep 1990 & -1.56 & 8 & 5.8 \\
E6 & Aug 1988 & Dec 1988 & Jan 1989 & -1.60 & 6 & 5.7 \\
E7 & Jun 2017 & Oct 2017 & Nov 2017 & -1.66 & 6 & 5.6 \\
E8 & Nov 2001 & Nov 2001 & Apr 2002 & -1.80 & 6 & 5.4 \\
E9 & Sep 2007 & Oct 2007 & Dec 2007 & -1.74 & 4 & 5.1 \\
E10 & Dec 1991 & Dec 1991 & May 1992 & -1.72 & 6 & 4.9 \\
\hline
\end{tabular}

Table 3. This selection was made to develop further analysis based on extreme meteorological dry conditions. In this table are also represented the onset, peak, end, peak value, duration, and severity of each episode. This information is also summarized for all dry episodes revealed by the SPEI1 from 1980 to 2017.

Through the SPEI it was not possible to know independently the role of the precipitation or an $\mathrm{Et}_{0}$ value in the occurrence and magnitude of the drought. This is why in Fig. 6 the accumulated precipitation during each drought episode (solid lines, denoted as E1-E10) listed in Table 3 are illustrated, as well as the monthly accumulated percentiles 5 (P05), 25 (P25), and 50 (P50) of precipitation for the same climatological period (1980-2017; discontinued lines). The order of the episodes in this figure is determined by the month of their beginning. Accumulated precipitation during June and July of E1 was between the P05 and P25 but later was between P25 and P50. In E7 the accumulated precipitation was between P25 and P50 from June to August, and afterward, from September to November it was drier still (between the P05 and P25). For all 10 episodes, the accumulated precipitation was never above P50, confirming the precipitation deficit. However, in some episodes that are more severe than others, the accumulated value of precipitation is higher (e.g. E3, E4, and E10), indicating that potential evapotranspiration played a crucial role in determining the magnitude of drought.

In Fig. 7 six annual leading modes of the EOF are shown, which explained $94 \%$ of the total spatial variability of the SPEI1 for those months when the SPEI $1 \leq-0.84$ in the MLSHD (represented in Fig. 5b). These represented potential physical modes of drought variability in the MLSHD. The first eigenvector (EOF1) explained $61 \%$. This pattern was very homogeneous, with close negative values in all the MLSHD. This indicates a great spatial homogeneity of the main drought pattern and the predominant influence of largescale factors. Although, a visual analysis of the EOF1 also shows a small longitudinal difference with more intense negative values on the eastern part of the MLSHD (farther from the coast). As expected, the characteristics of the following EOFs represented in Fig. 7 show major spatial differences. The EOF2 explained $17 \%$ of the total drought variability. In it, the major differences were observed between the eastern part of the region, where positive values prevailed, and the rest of the territory with negative values, indicating different spatial drought magnitudes. In Fig. 1 it can be observed that the eastern of the MLSHD is characterized by major elevation. Therefore, spatial drought variability in this pattern 


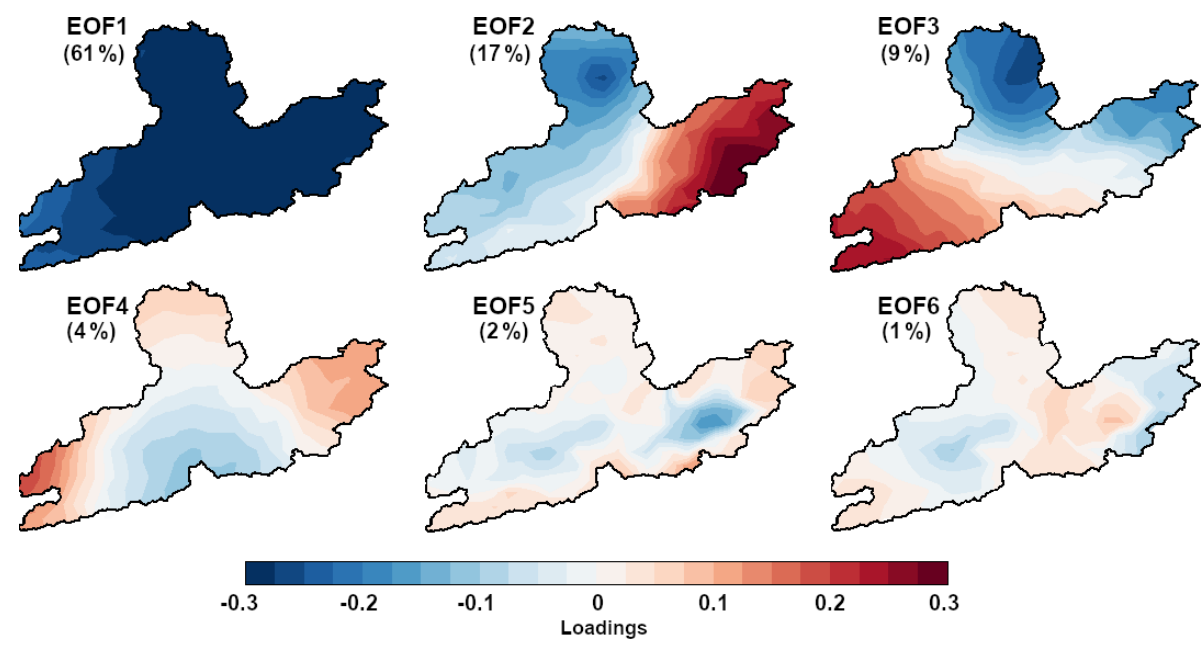

Figure 7. Six leading modes of the EOF for the months characterized by average SPEI1 values $\leq-0.84$. The numbers between parentheses correspond to the amount of variance explained by each EOF.

can be explained by orographic differences. The EOF3 explained $9 \%$ of spatial drought characteristics, which were determined by a gradient from positive to negative values from the coastal zone to the northeast, respectively. The remaining EOFs showed greater spatial variability and lower percentages of explained variance.

\subsection{Relationship between the circulation weather type classification and drought conditions}

The MSLP fields and anomalies for the 10 pure CWTs responsible for the major variability in atmospheric circulation over the IP are shown in Fig. 8. These anomaly composites were obtained after removing the respective means computed for the period of 1981-2010. Here we aimed to determine the association of large-scale atmospheric circulation over the IP with drought conditions that affected the MLSHD during 1980-2017. The reddish (blueish) isolines in Fig. 8 identify the higher (lower) values in the MSLP absolute fields and the positive (negative) values of MSLP anomalies. The NE configuration (Fig. 8a) was characterized by a transition from a strong high-pressure region over the eastern Atlantic Ocean extending to northwestern Iberia and the MLSHD, with lower pressures over Africa. The anomaly field (Fig. 8b) shows that this high-pressure centre was displaced towards the northeast, to the west of the United Kingdom (UK). Figure 8a shows that in the E configuration the high-pressure system was shifted northwards and centred over the Cantabrian Sea and the Celtic Sea, while in the SE circulation it was centred over France and the southern UK. The anomaly fields (E and SE; Fig. 8b) show an intensification of 8 to $10 \mathrm{hPa}$ of these high-pressure systems. In the $S$ pattern, higher pressure values occurred over central Europe, and lower pressure values $(1010 \mathrm{hPa})$ occurred over the northeastern Atlantic (Fig. 8a), which were up to 8
$10 \mathrm{hPa}$ lower (Fig. 8b). In the SW CWT high-pressure values were limited to the most southern areas in the North Atlantic and a well-developed low-pressure system $(1000 \mathrm{hPa})$ was located over the northeastern Atlantic (Fig. 8a). The anomaly fields show an intensification of these systems to the northwestern region of Iberia - up to $-20 \mathrm{hPa}$ (Fig. 8b). In the $\mathrm{W}$ and NW configurations, the low-pressure systems were shifted northwards and northeastwards towards the UK, respectively, while the Azores High was established (Fig. 8a). The corresponding anomaly fields illustrate the intensification of these low-pressure systems (Fig. 8b). The highpressure systems identified in the case of the NW configuration were more intense in the $\mathrm{N} \mathrm{CWT} \mathrm{(Fig.} \mathrm{8a),} \mathrm{and} \mathrm{the}$ anomaly shows a northward displacement of these systems, covering all the Atlantic regions, while low-pressure systems were more developed over the Gulf of Lion, in the Mediterranean (Fig. 8b). Finally, the C CWT represented low relative pressures located over the western IP (Fig. 8a) which intensified, while positive anomalies developed for the northern regions, west of the UK (Fig. 8b). The opposite occurred for the A configuration, which represents an intense Azores High, as it extended towards Europe (Fig. 8a). This anomaly shows that under these conditions the high-pressure systems intensified over the IP and southwestern Europe (Fig. 8b).

The correlations between the monthly percentage values of the occurrence of each of the pure CWTs with the SPEI1 time series are shown in Fig. 9. CWTs and SPEI1 time series were de-trended before correlation computation. The significant positive correlations found with SW, W, and NW CWTs are in agreement with the results of Russo et al. (2015), but they also relate to the entire NWIP. Indeed, air masses from the SW, W, NW, and C configurations are usually associated with inbound baroclinic structures, Atlantic storms, and atmospheric rivers (Eiras-Barca et al. 2018) which carry moisture from the Bay of Biscay (BB) and the tropical- 
(a)
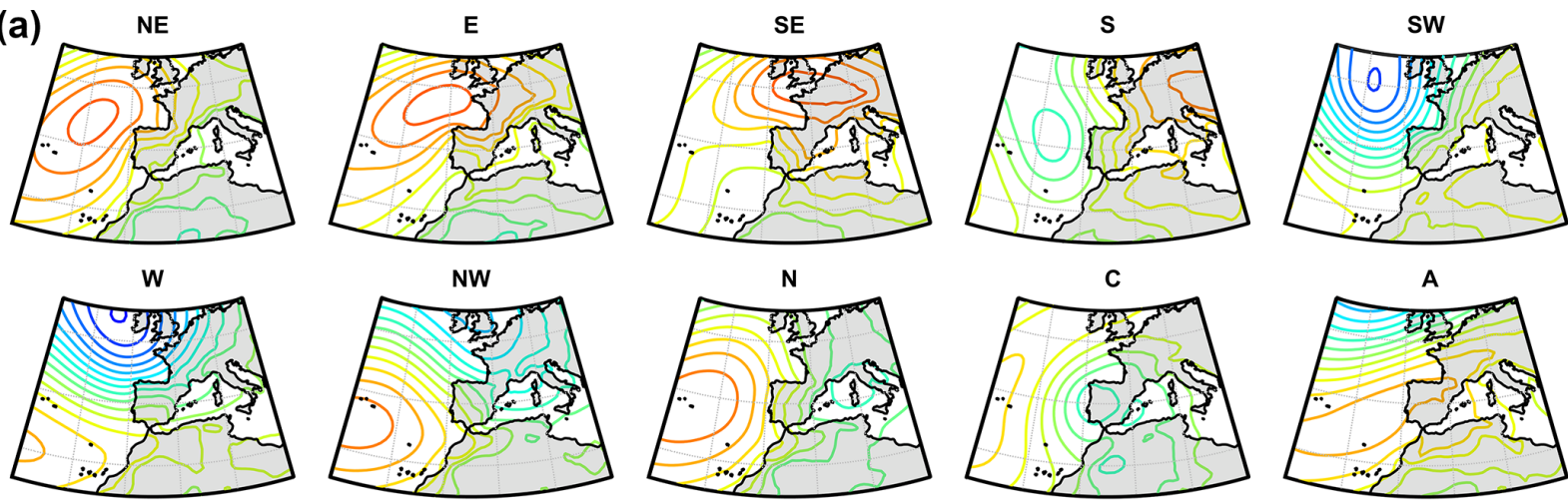

N

C
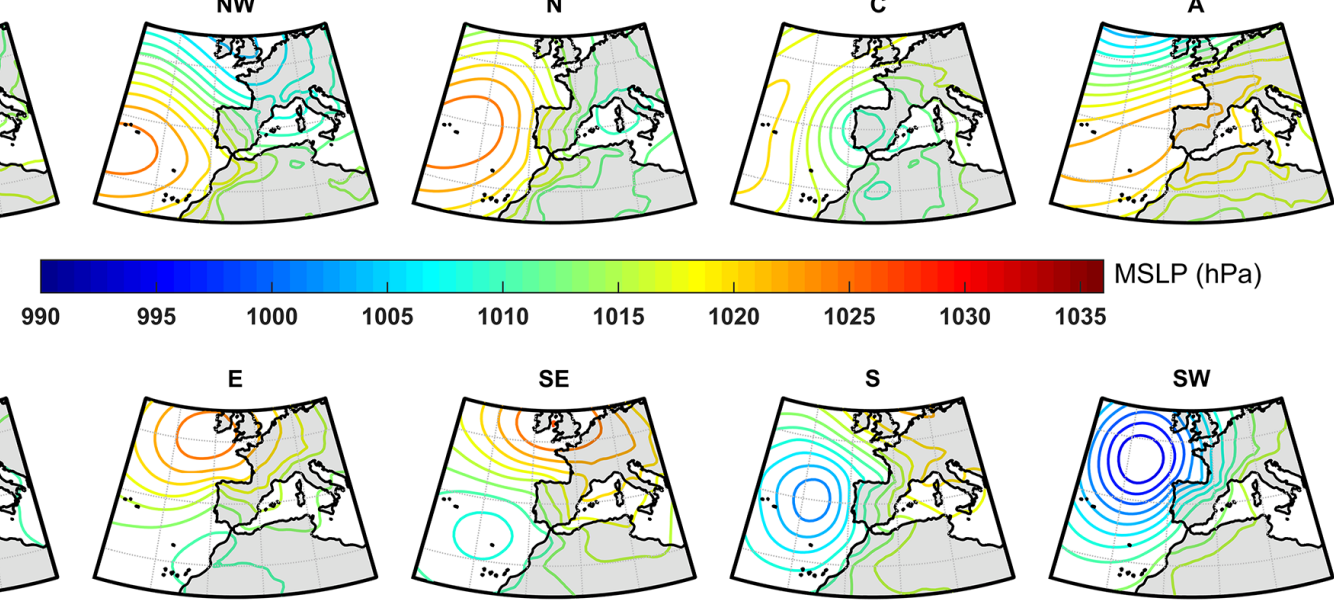

NW
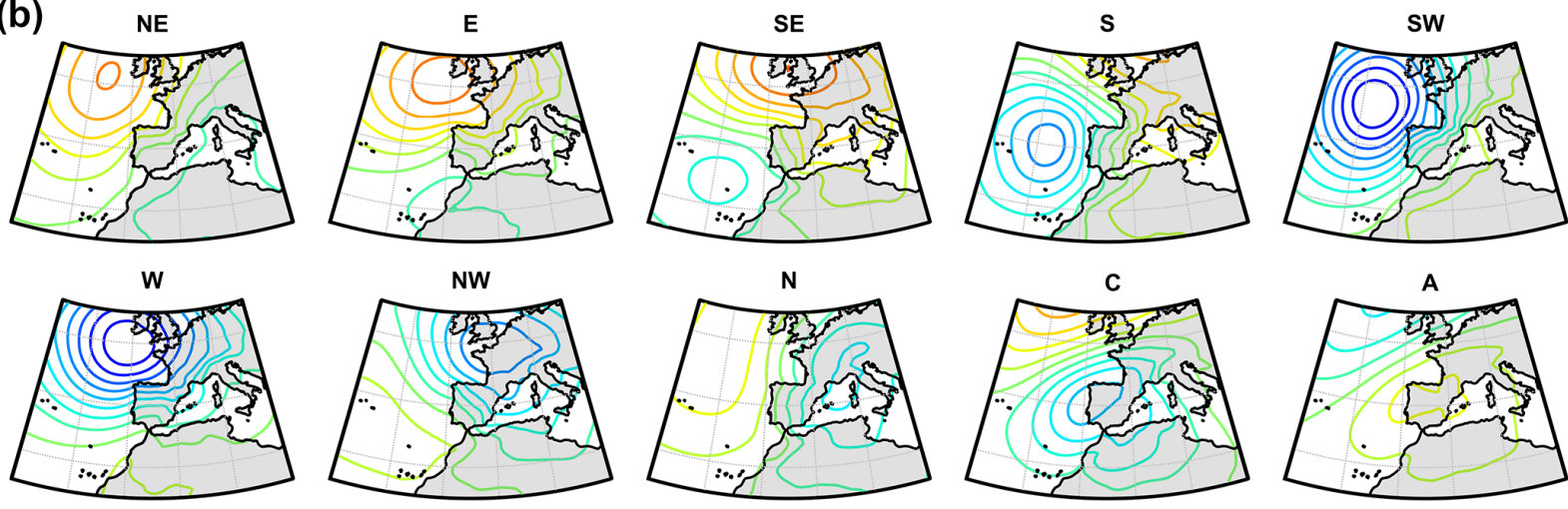

C
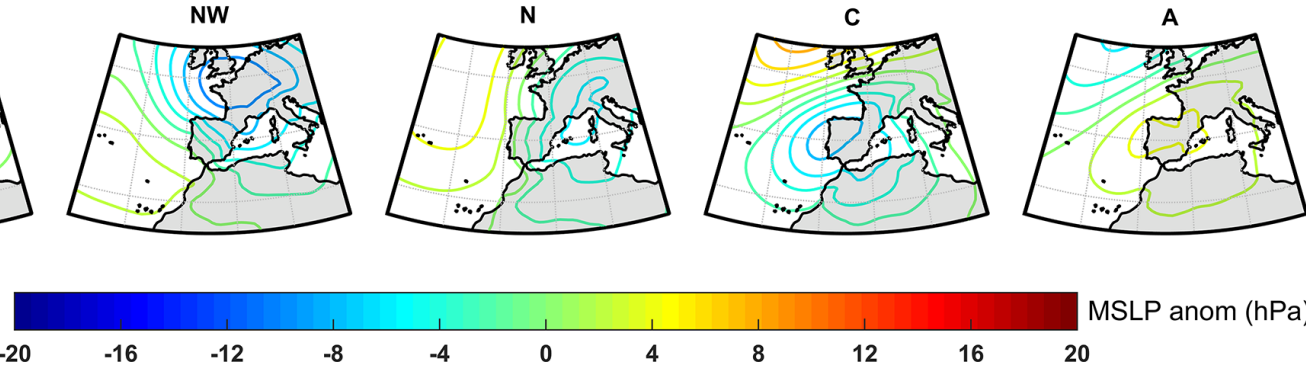

MSLP anom (hPa)

Figure 8. (a) Mean sea level pressure (MSLP) fields and (b) anomaly (anom) field configuration of the 10 pure circulation weather types (CWTs) for the period of 1980-2017. The contour interval is $2 \mathrm{hPa}$.

subtropical North Atlantic corridor to the MLSHD, both of which are principal sources for precipitation over Galicia and northern Portugal (Drumond et al., 2011). The CWT appears to be mostly positively correlated with the SPEI1; however, for almost all months the correlations were not statistically significant. The extratropical cyclones and the associated synoptic-scale fronts reaching the IP during winter months and early spring normally produce large accumulated rainfall and are thought to play an important role in the hydrological cycle in northern Portugal and Galicia (Paredes et al., 2006; Añel et al., 2014; Hénin et al., 2019).

Contrastingly, the atmospheric circulation associated with NE, E, and SE CWTs was negatively correlated with the SPEI1 time series in all months, thereby suggesting that air masses associated with these were directly related to the dry conditions in the MLSHD. Negative correlations between the SPEI1 and the A CWT mostly occurred during winter months; however, these were lower and not significant during several of those months. On the contrary, the correlations between the SPEI1 and C configuration are mostly pos- itive but mostly not statistically significant. Finally, as expected, monthly correlations between the atmospheric circulation associated with the $\mathrm{N}$ and S CWTs with the SPEI1 generally had opposite sign values, in addition to being very low and not statistically significant. Trigo et al. (2004) associated the mean annual and seasonal rainfall decrease across the IP during the second half of the 20th century to the lower occurrence of the high-rainfall circulation types (cyclonic) and with the increase of the low-rainfall types (anticyclonic). However, trend analysis for the period of 1980-2017 (not shown) revealed no statistically significant trend in the series of any CWT.

The spatial patterns of correlations between the detrended series of the SPEI1 and the climatic teleconnections indices appear in Fig. 10. In most of the patterns, no different signs of the correlation were observed, coinciding with the sign of the correlation shown in Fig. 9. This confirms that there was a homogeneous influence of each CWT on the variability of dry and wet conditions in the MLSHD according to the SPEI1. However, local variations of the correlation were still 


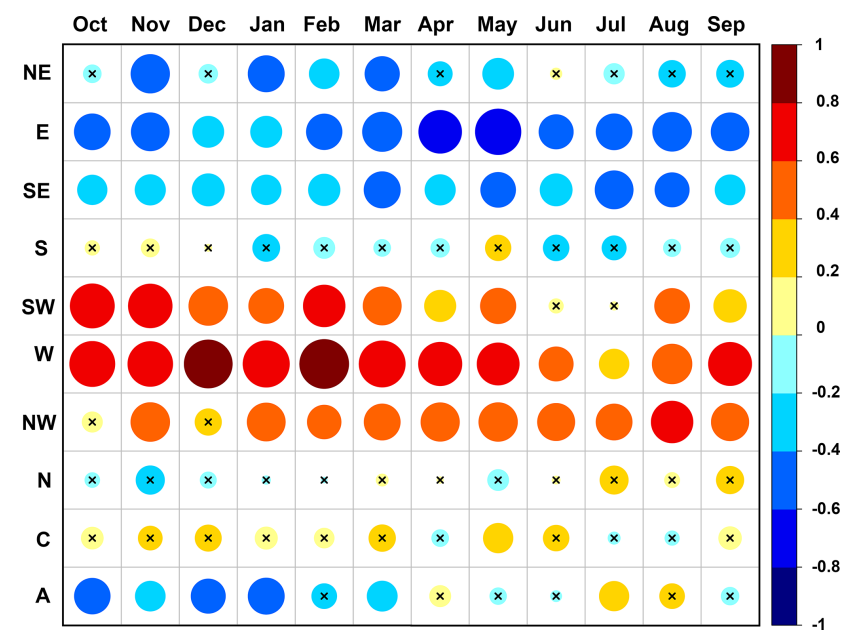

Figure 9. Correlations between the detrended series of the SPEI1 and the monthly percentage of occurrence of each of the pure CWTs for 1980-2017. The size of the circles is proportional to the correlation values. The $\mathrm{x}$ symbols inside the circles represent statistically non-significant correlations at $p<0.05$.

observed. For example, the spatial correlations of the SPEI1 with the W and E CWTs show a west-east gradient from highest to lowest values. The correlations were statistically significant throughout the MLSHD only for the SE, E, SW, W, and NW CWTs.

In order to understand how distinct CWTs might have affected drought severity in the MLSHD, Fig. 11 shows the monthly frequency (expressed in percentage) of each CWT under different drought categories (moderately dry, severely dry, and extremely dry) according to the SPEI classification shown in Table 1 . Those Octobers under moderately dry conditions were associated with the prevalence of A, E, and C CWTs. Octobers affected by severely dry conditions were associated with a major percentage of A circulation, but for those under extreme drought conditions, it seems that $\mathrm{E}$ circulation highly increased with respect to previous drought categories, while there was a slight decrease in the frequency of A circulation. For those Novembers affected by moderate, severe, and extreme drought conditions, the most frequent CWT was the A circulation, which imposed an atmospheric flux from the north. For severely and extremely dry Decembers the frequency of CWTs changes with respect to those of previous months, and an increase in the percentage of SE circulation was observed. Januaries under moderate and severe drought conditions were characterized by a major percentage of atmospheric conditions governed by the A pattern. In February, the percentage of occurrence of the A CWT decreased when drought severity increased, while the E CWT increased for severely drought months, and the NE CWT increased for extreme drought months. For those Marches under drought conditions, the most frequent patterns were the A, E, and NE CWTs. The frequency of CWTs for those
Aprils affected by drought conditions was remarkably different with respect to those described for previous months. In these months the E and SE CWTs were directly related to drought severity increase. The following months (May to September) were affected by different drought categories; the combination of NE, E, and A CWTs was the most frequent according to the percentage observed in Fig. 11.

Figure 12 shows the accumulated SPEI1 (red line) during the 10 most severe drought episodes listed in Table 3. The coloured areas in this figure represent the CWTs that occurred for every day of the episode. CWTs were grouped taking into account the monthly correlation results presented in Fig. 9. A visual analysis found that, along with the temporal evolution of all episodes, the most frequent CWTs were the eastern (NE-E-SE; yellow colour) and A (orange colour) CWTs. In agreement with results thus far described, for most of the episodes, the eastern circulation seems to be especially related to the drought intensification, being the most common CWT during the peak month of each event. Western circulation patterns appeared randomly during the episodes. In the last days of E1, E5, and E6, the SW, W, and NW CWTs were observed, while in the last days of E2, E3, and E7, the C CWT was observed.

The anomaly in the percentage of occurrence of every pure CWT during the 10 most severe episodes is shown in Fig. 13. The anomaly was calculated for the complete duration of each drought episode and referred to the 1980-2017 mean value for the same months. The eastern (NE, E, and SE), A, and S CWTs experienced mostly positive anomalies, in accordance with the results described for Fig. 12. Conversely, in most of the episodes the anomaly of the westerncirculation (NW, W, SW), N, and C CWTs decreased. The largest negatives anomalies appeared for the W CWT, which had an average between $2.5 \%$ and $5.7 \%$. Similar results were observed when the total number of severe events was considered (Fig. S1 in the Supplement).

Figure 14 shows the anomaly of the VIMF and its divergence for the onset, peak, and termination of drought episodes listed in Table 3. E1 was the driest and was associated with anticyclonic circulation of the VIMF with its centre located to the southwest of the MLSHD. This centre moved to the north during the peak of the episode, imposing moisture flux anomalies from the northeast. This was supported by prevailing A and NE CWTs, which decreased in percentage when the drought disappeared (February 2017), in accordance with the major frequency of $\mathrm{C}, \mathrm{W}$, and $\mathrm{SW}$ circulation and negative anomalies of the VIMF divergence (favouring the convergence). E2 began in September 2012. For this month, intense positive anomalies of the VIMF divergence over the MLSHD were observed, which were a dynamic limitation for the occurrence of precipitation. The A and NE CWTs were the most frequent CWTs during that month. The peak of this episode occurred in February 2012, when intense anticyclonic anomalies of the VIMF with its centre near the southwest of Ireland dominated the North Atlantic sector. 

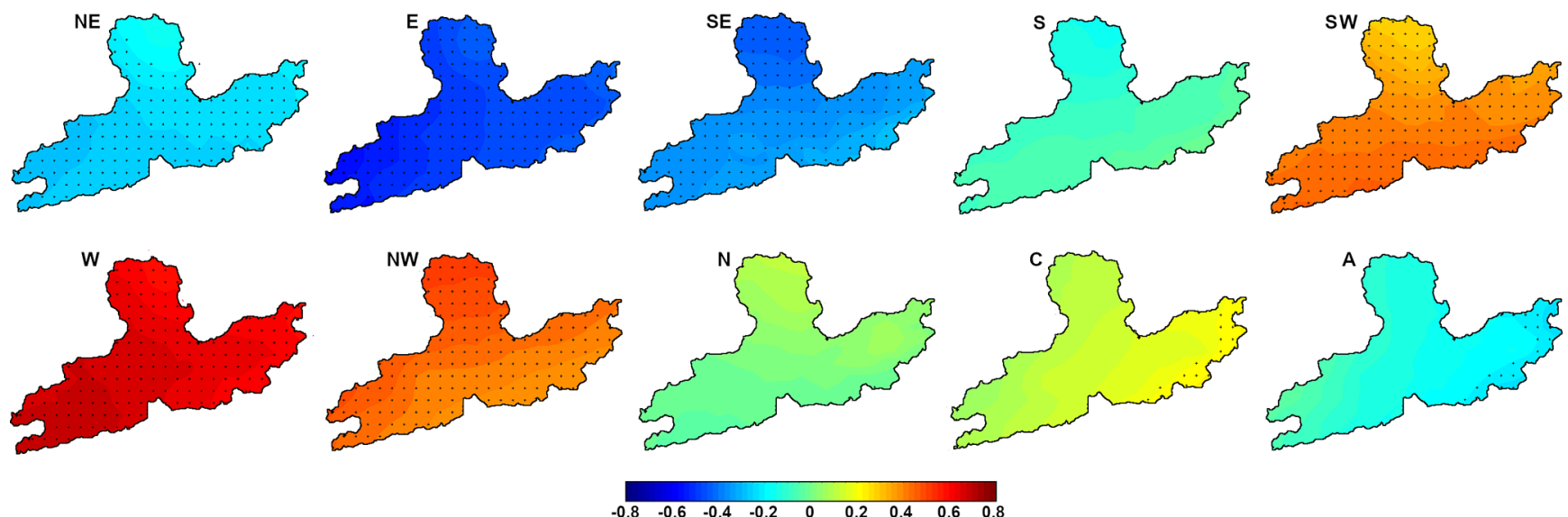

Figure 10. Spatial correlations between detrended grid series of the SPEI1 at a resolution of $0.1^{\circ}$ in longitude and latitude and detrended monthly percentages of occurrence of each of the pure CWTs for 1980-2017. The dots in every correlation map denote statistically significant correlations at $p<0.05$.

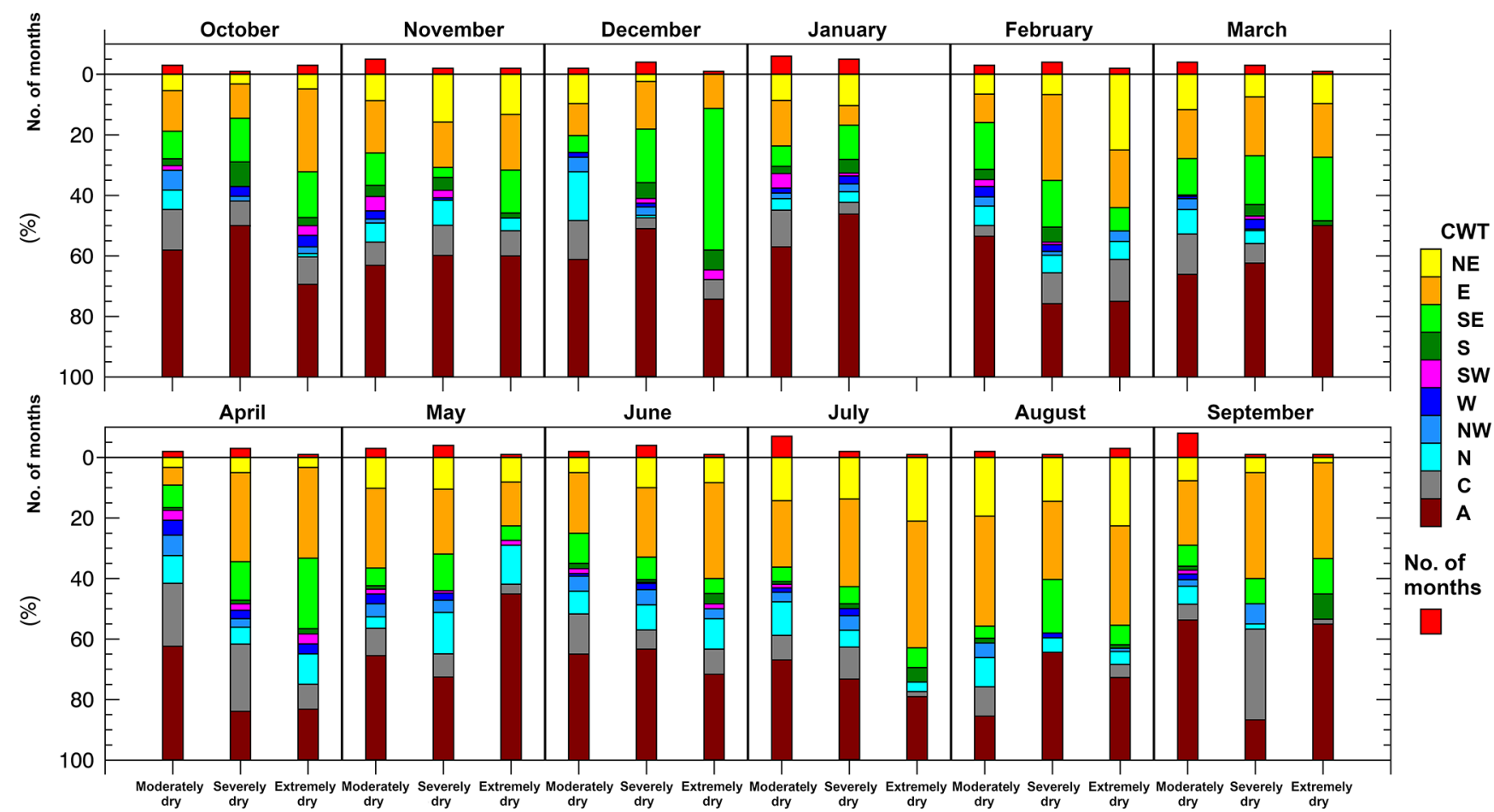

Figure 11. Monthly percentage of occurrence for every CWT associated with moderately, severely, and extremely dry conditions. The red bars represent the number of months the MLSHD was affected by each drought category.

In accordance, $\mathrm{NE}$ and $\mathrm{E}$ circulations were the most frequent over the IP. Drought conditions disappeared (in April 2012) when negative anomalies of the VIMF divergence in association with cyclonic circulation anomalies of the VIMF with its centre located over England affected the MLSHD. Correspondingly, the most frequent circulation patterns during that month were the C and NW CWTs. The third and fourth driest episodes began in December of 2014 and 2003, respectively. In both months, the A CWT was the most prominent circu- lation pattern. Anticyclonic anomalies of the VIMF with its centre over the North Atlantic affected the MLSHD; these anomalies were more intense in December 2014, when positive anomalies of the VIMF divergence covered almost all of the IP. The peak of E3 occurred in June 2015 with intense VIMF anomalies from the Atlantic Ocean that reached the northern portion of the IP; however, over the MLSHD, both negative and positive VIMF divergence anomalies were observed. The last month of E3 was August 2015 because 


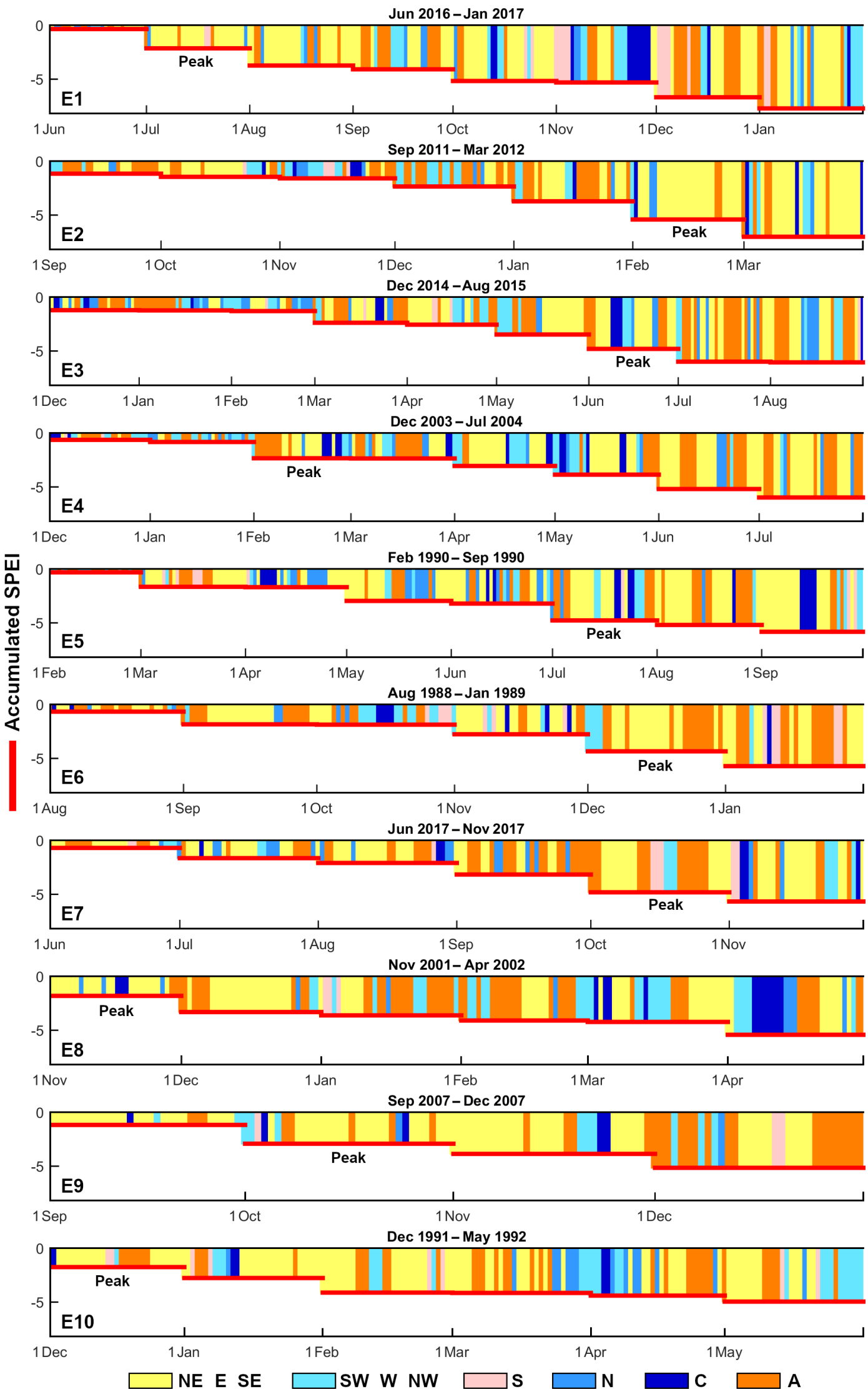

Figure 12. Accumulated SPEI1 (red line) and grouped CWTs during the 10 most severe drought episodes listed in Table 3. 


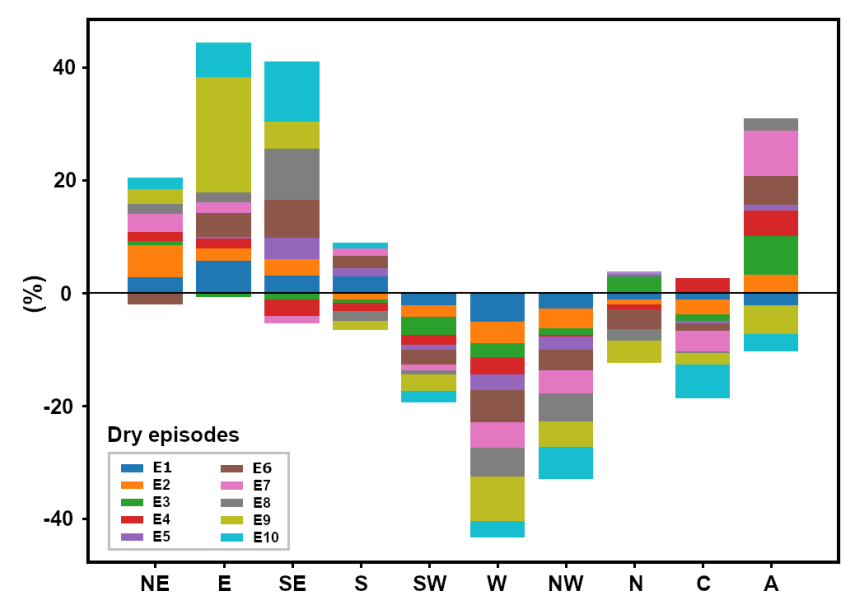

Figure 13. Anomalies in the percentage of each CWT associated with the 10 most severe drought episodes listed in Table 3.

the SPEI changed to a positive value in September 2015 owing to negative anomalies of the VIMF divergence over the NWIP and the influence of VIMF anomalies reaching the MLSHD from the northwest. This was in accordance with an increase in the percentage of the W CWT with respect to that in the previous stage of the episode. In the peak of $\mathrm{E} 4$, positive anomalies of the VIMF divergence over the MLSHD were observed. This episode ended when the anomalies on the moisture flux from the west favoured the occurrence of convergence, despite the fact that the most frequent CWT was the A CWT, followed by the W CWT. E5 began in February 1990. In that month, the VIMF anomalies over the IP showed an intense anticyclonic circulation accompanied by positive divergence anomalies over all the IP and consequently, a high frequency of A circulation. In the peak there is no clear pattern of VIMF divergences; however, 1 month after the demise the SPEI1 became positive due to negative anomalies of the VIMF divergence and enhanced moisture flux reaching the MLSHD from the northwest.

In August 1988 the VIMF anomalies in the onset of E6 were characterized by an anticyclonic circulation centre to the southwest of the MLSHD and cyclonic circulation in the northwest, which were both over the Atlantic Ocean (Fig. 14) and enforced VIMF anomalies reaching the MLSHD from the west. Nevertheless, the VIMF divergence anomalies showed prevailing divergence conditions. That is, the MLSHD could receive air masses from the west, which, as already described, were associated with the increase of wet conditions, but dynamic atmospheric conditions could inhibit the occurrence of precipitation. In the peak of this episode (December 1988), a centre of anticyclonic circulation of the VIMF was observed in the North Atlantic Ocean to the northwest of the IP that produced an intense divergence of the VIMF over the MLSHD. The predominant frequency of the $A$ and $E$ circulations were also observed for that month. That episode ended when VIMF anomalies reached the MLSHD from the northwest, in combination with negative anomalies of the VIMF divergence over the MLSHD. In the onset of E7, as well as in E6, a centre of anomalous cyclonic circulation of the VIMF was observed in the North Atlantic Ocean to the northwest of Ireland. That situation was different at the peak of the episode (October 2007). In that month, anticyclonic circulation of the VIMF with the centre located to the northwest and near the MLSHD imposed strong divergence of the VIMF over the MLSHD, while the prevailing frequency of A and E CWTs occurred. In December 2017 this centre was located further west, and the VIMF divergence anomalies became negative over the MLSHD, while the SPEI1 turned out to be positive. In E8, the onset (November 2001) coincided with the peak of the episode. That month was characterized by the prevalence of the E and NE CWTs and positive anomalies of the VIMF divergence associated with the strong anomalous anticyclonic circulation of the VIMF over the North Atlantic Ocean. That episode ended in April 2002 owing to a positive SPEI1 1 month after the demise (May 2002). A small area of negative VIMF anomalies over the MLSHD was observed for that month. As well as in the previous episodes, the onsets of E9 and E10 were characterized by anticyclonic anomalies of the VIMF with the centre located to the northwest of the MLSHD over the Atlantic Ocean. The strong VIMF divergence was observed over the MLSHD in the peak of E9 and the onset of E10. The onset and peak of E10 coincided. The VIMF anomaly pattern for that month (December 1991) was characterized by anticyclonic circulation with the centre located in the North Atlantic Ocean to the northwest of the MLSHD near Ireland. This pattern was very similar for the peaks of E9, E2, E5, E6, and E7. Both episodes E9 and E10 ended owing to negative anomalies of the VIMF divergence (especially for E10).

\subsection{Relationship between drought and modes of climate variability}

Figure 15a shows the correlation between the BEST, NAO, EA, AO, SCAND, and WeMOi series with the SPEI1 up to the SPEI24. This analysis helps to determine any causal effect between atmospheric and oceanic teleconnection patterns and dry and wet conditions in the MLSHD. The results reveal a major link between the SCAND (positive correlation) and $\mathrm{AO}$ (negative correlation), particularly at short temporal scales of the SPEI (1 to 4 months). The SCAND pattern (initially referred to as the Eurasia- 1 by Barnston and Livezey, 1987) in its positive phase was characterized by positive height anomalies over Scandinavia and western Russia but weaker centres of the opposite sign over southern and western Europe. The negative phase showed the opposite pattern. The results of Rodríguez-Puebla et al. (1998) show heterogeneous spatial correlation between the SCAND index and the annual precipitation over the IP; however, they confirmed that annual precipitation variability in the northwestern IP was related to the SCAND December pattern. On 

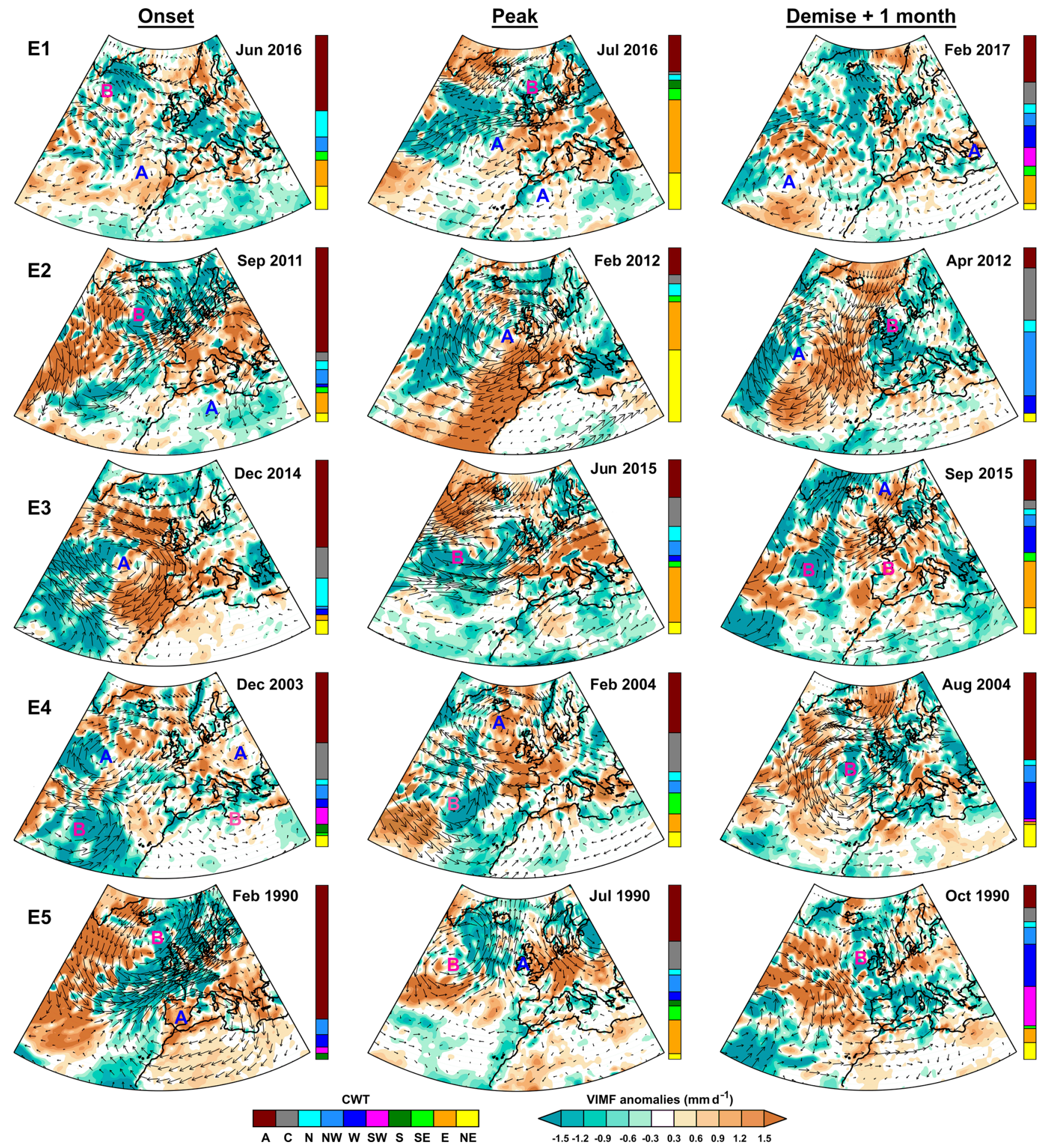

Figure 14.

the contrary, another study showed that the AO ranged from positive to negative values depending on pressure anomalies in the Arctic region (Thompson and Wallace, 1998). A band of strong winds circulating around the North Pole associated with the positive phase of the AO kept colder air within the polar region and corresponded to a deepening of the Azores High and the strengthening of the polar and subtropical jets over the Euro-Atlantic region (Ambaum et al., 2001). In the negative phase, this ring is thought to become weaker, thereby allowing the southwards penetration of Arc- 

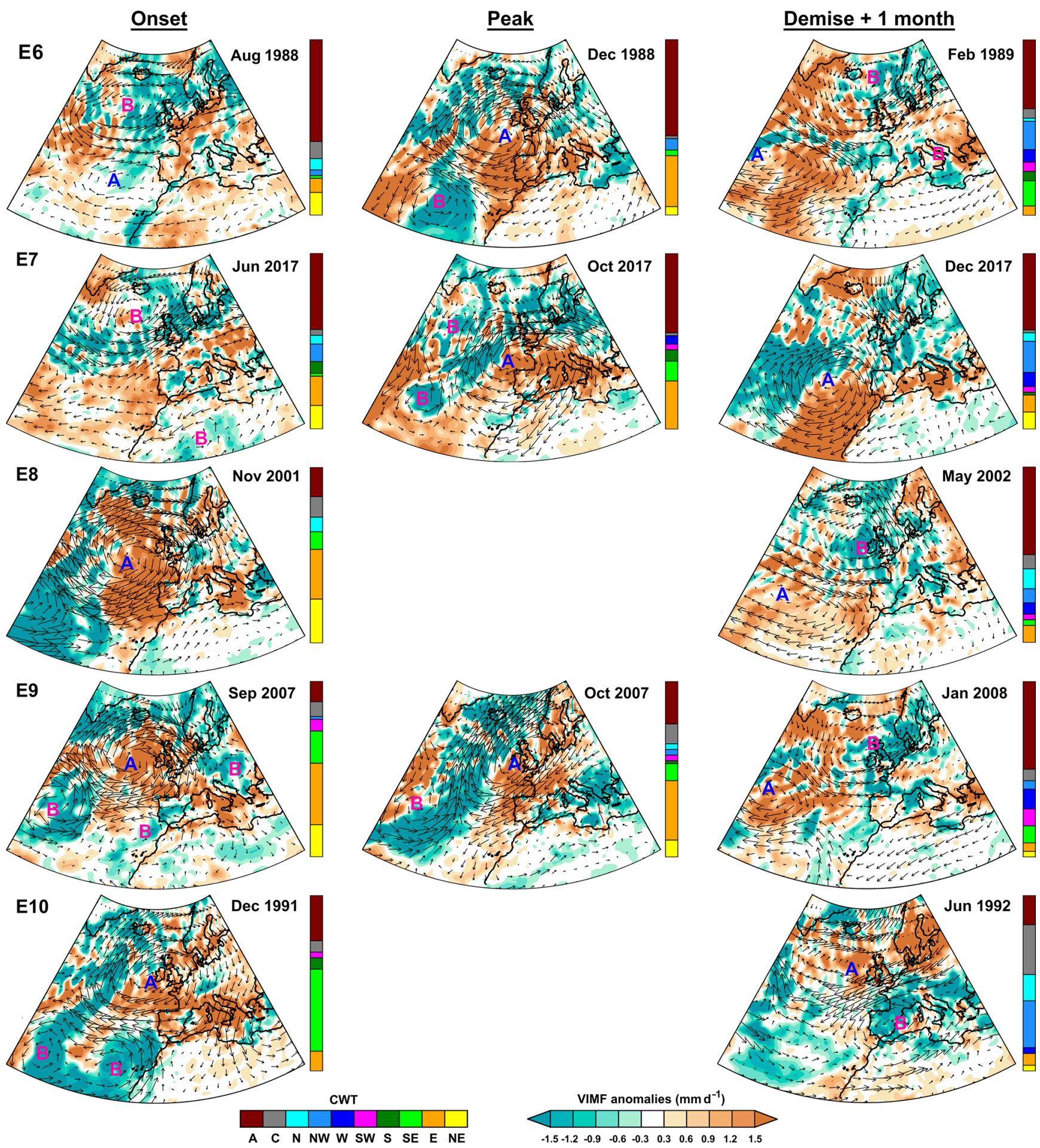

Figure 14. The monthly anomaly of the VIMF (in arrows) and its divergence (shaded) during 1980-2017 for the onset, peak, and 1 month after the termination of each of the 10 most severe drought episodes (Es) listed in Table 3. Anticyclonic (or cyclonic) centres of the VIMF anomalies circulations are represented as A (or B). Vertical bars show the monthly percentage of each pure circulation weather type (CWT). 
tic air masses and an increase in the magnitude of the total eddy energy fluxes into the Euro-Atlantic region (Rivière and Drouard, 2015), which would affect the hydroclimatic conditions in the northwestern IP (deCastro et al., 2006a) and this explains the negative correlations obtained with the SPEI in this study.

According to Wanner et al. (2001), the AO is similar to the NAO in many aspects. Multiple results have shown a strong relationship between the winter tropospheric pattern of the NAO and AO (Wanner et al., 2001; Rogers and McHugh, 2002; Hurrell et al., 2003; Dai and Tan, 2017). However, although the $\mathrm{AO}$ is strongly correlated with the NAO, it does not show the recent sustained significant summer decrease, but it does show enhanced early-winter variability (Hanna et al., 2015). The results of Tabari and Willems (2018) show that the AO signal is oppositely related to anomalies of daily precipitation extremes during summer in the NWIP, a phenomenon they did not see occurring with the NAO. Therefore, in order to assess any possible difference in the impacts over drought conditions, both indexes were used in this investigation. The negative phase of the NAO was associated with the weakness of the Azores High and a southwards position in the storm tracks, thereby resulting in wet conditions over the IP (Trigo et al., 2002). The correlations in Fig. 15a demonstrate that both the NAO and $\mathrm{AO}$ relationships with the SPEI were nearly identical across different temporal scales. However, the correlations with the $\mathrm{AO}$ are greater, indicating that the AO index may be more effective for explaining the atmospheric influence on dry and wet conditions in the MLSHD. Nevertheless, the NAO index has also been traditionally defined as the normalized pressure difference between a station on the Azores and one on Iceland (Hurrell, 1995; Jones et al., 1997); therefore, the correlations with the SPEI could be also different in this regard.

The correlations between the SPEI and the BEST index are positive but also very low $(<0.2)$ and not significant; moreover, these became negative when correlations were made with SPEI values computed from the past 6 to 24 months but were also not statistically significant (Fig. 15a). ENSO is namely the strongest ocean-atmosphere coupling phenomenon on the interannual timescale, but our results suggest a poor association between ENSO (El Niño and La Niña) and the occurrence of dry and wet conditions in the MLSHD. The findings of García et al. (2005) revealed that ENSO influence was not significant on the precipitation over Galicia. Though, according to Dai and Tan (2017), a warm (cold) ENSO enhanced the negative (positive) AO phase, which is directly related to the MLSHD hydroclimate. Finally, the correlations between the SPEI1 to the SPEI24 with the WeMOi and EA were positive but only statistically significant for the WeMOi within the first two temporal scales of the SPEI.

Because the correlations in Fig. 15a are greater with the SPEI1 than with other temporal scales of this index, a second correlation analysis was conducted in order to determine the relationships between the SPEI1 and the teleconnections phenomena but at monthly scale (Fig. 15b). The correlations with the BEST index are mostly not statistically significant. Negative correlations only occur in spring (March, April, and May; Fig. 15b). To the contrary, Muñoz-Díaz and Rodrigo (2004) found that the negative phase of ENSO, La Niña, leads to a low probability of drought in spring but for the whole northern IP, while Lorenzo et al. (2010) also concluded that La Niña almost always announces dry springs in the NWIP. Unlike these authors in this study, we use an index that contemplates ocean and atmospheric conditions to identify the phases of ENSO, and another index that contemplates both precipitation and evapotranspiration to identify drought conditions. In any case, this issue deserves further study.

The monthly correlations obtained between the NAO and AO with the SPEI1 were very similar (Fig. 15b); however, as expected from the results already described for Fig. 15a, the AO was best related with the SPEI1 series and consequently to monthly dry and wet conditions in the MLSHD throughout the hydrological year, especially in the winter and spring months (December to March). This is in agreement with Manzano et al. (2019), who argued that the AO and NAO patterns have a significant impact on droughts in winter over large areas of the IP. However, at local and regional scales, results may differ. In a previous study by RodríguezPuebla and Nieto (2010), it was revealed that positive (negative) NAO induced an east-west decreasing gradient of drier (wetter) conditions over the IP. The most recent findings of Sáez de Cámara et al. (2015) describe a complete lack of correlation between $P$ anomalies and the NAO for the central and eastern parts of the northern IP. These authors also have shown that from the late 1980s to 2005 an increase occurred in the frequency of extreme circulation modes within each of the NAO positive and negative phases, both inducing negative precipitation anomalies and a long-lasting dry spell in the northern IP. That is, special consideration must be made when associating a positive trend of the NAO with the increase of dry conditions over the entire IP. In this study, positive correlations between the EA and SPEI1 were observed in the winter and spring months (November to May). Results of Casanueva et al. (2014) also revealed a positive correlation of the EA with the $P$ values and the consecutive wet days over the NWIP during the boreal winter. The SCAND pattern was also positively correlated during all months of the year, but no significant correlations were found in December, February, and March. This means that the negative phase of the SCAND pattern was related to dry conditions in the MLSHD. During the negative phase, the European trough was thought to deepen, while weak pressure ridges were observed over the northeastern Atlantic Ocean (Bueh and Nakamura, 2007). This caused the Atlantic storm track to extend northeastwards, affecting a vast area from northern Europe to central Siberia. Finally, in this study the WeMOi showed positive significant correlations with the SPEI1 from January to November but especially during the boreal summer months. 

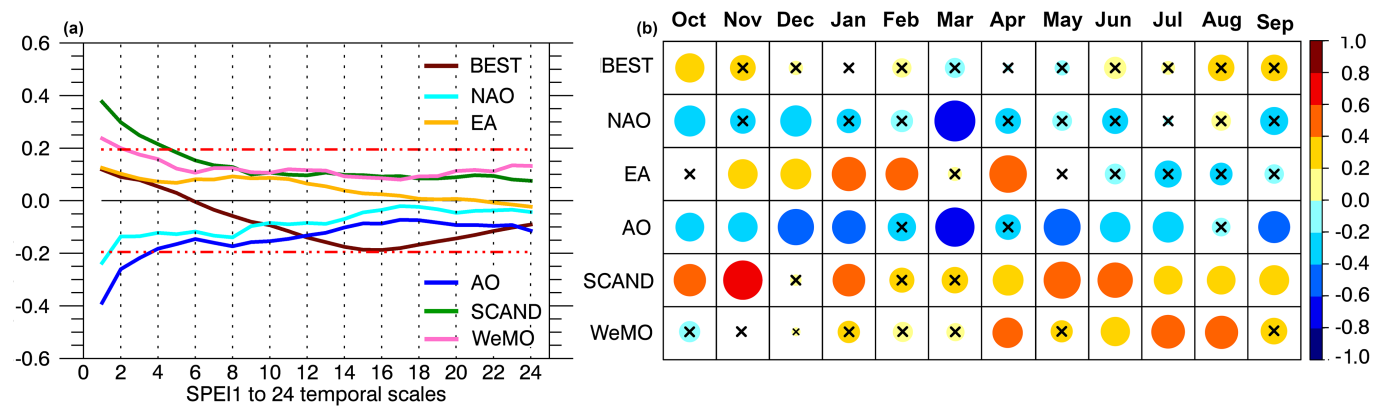

Figure 15. Correlation between the monthly series of the bivariate El Niño-Southern Oscillation (BEST), North Atlantic Oscillation (NAO), East Atlantic pattern (EA), Arctic Oscillation (AO), Scandinavian pattern (SCAND), and the Western Mediterranean Oscillation (WeMO) with (a) monthly series of the SPEI1 to the SPEI24 and (b) the monthly correlation between the same climatic indices and the SPEI1 for the period of 1980-2017. Statistically non-significant correlations at the $95 \%$ confidence level are those within discontinuous red lines in (a) and marked with an $\mathrm{x}$ in (b). The size of each circle is proportional to the correlation value.

Previously, the WeMOi had been associated with the precipitation variability in the eastern part of the IP and the south of France (Martín-Vide and Lopez-Bustins, 2006; Martin-Vide et al., 2008). However, these correlations (Fig. 15b) indicate that this index could be also useful for explaining dry and wet conditions in the NWIP. In this study, the positive phase of the WeMO corresponded to the anticyclone over the Azores which may have transported moisture entering the MLSHD from the west, and as previously explained, the west circulation favoured the occurrence of wet conditions in the MLSHD, which is in agreement with the positive correlations found. In its negative phase, the WeMO is thought to coincide with the low pressure often cut off from northern latitudes, in the framework of the Iberian southwest (MartínVide and Lopez-Bustins, 2006). It possibly favours the east circulation over the NWIP, which may also explain the positive correlation between the WeMOi and SPEI1 noted in this study.

The frequency bands and time intervals of the covariations between the SPEI1 and different modes of climate variability represented by climatic indices (i.e. BEST, EA, WeMOi, NAO, AO, and SCAND) are shown in Fig. 16. The coloured shading displays the magnitude in the coherence as represented in the colour bar, which varies from 0 to 1 and indicates the timescale variability in the correlation between the two time series. Warmer colours (red) represent regions with significant interrelation, while colder colours (blue) signify lower dependence between the series. The results reveal that the BEST index showed strong but intermittently significant interannual coherence with the SPEI1 in the period of the 1-7-month band. Moreover, a significant correlation was observed from 1980 to 1990 for the 40-64-month band, but it was outside the cone of influence (COI) until the end of 1983. In this timescale, the arrows pointing straight down indicate that the SPEI led the BEST index by $90^{\circ}$. In the case of the EA there was a frequent, significant co-oscillation with the SPEI1 in the high-frequency 0-6-month band. However, from approximately the end of the 2000s to 2012 , a high coherence peak occurred in the low-energy regions (for nearly 30-50 months). The coherence between the SPEI1 and WeMOi exposed frequent but non-stationary interannual coherence regions at $1-8$ months. At $\sim 66$-month frequencies a strong positive coherence was noticed within the COI between 1992 and 2008.

The findings of Hurrell (1995) revealed that the NAO has a rich combination of high frequencies from intraseasonal to interannual timescales and a low frequency from decadal to multidecadal timescales. It had significant coherence with the SPEI at high frequencies (6 to 16 months) in the periods of 1982-1984, 1986, and 2004-2012 (Fig. 16), coinciding with dry periods in the MLSHD. Strong coherence was also noticed at a longer temporal scale (30 to 34 months) for the period of 1986-1993. Results of García et al. (2005) also suggest that the NAO and precipitation in Galicia could be related at a timescale of 8 years. For this study, compared with those in the NAO, oscillations in the AO were manifested in the SPEI1 over most of the period on intermittent wavelengths from 2 to 6 months but most significantly and for longer periods in the range of 6 to 36 months ( 3 years). In this frequency band, the left-pointing arrows show an anti-phase relationship (negative correlation), thereby indicating that the AO and SPEI1 moved in opposite directions from each other (i.e. when one was maximum, the other was minimum and vice versa). This is in accordance with previous correlations shown in Fig. 15. Finally, the significant coherence between the SPEI1 and the SCAND pattern reveals the influence of this teleconnection pattern between 1990 and 2005 along with the $0-8$-month periodic bands and at low frequencies (from approximately 14 to 40 months) during longer and continuous periods. Alternatively, arrows pointing to the right and downwards and right and upwards indicate alternately the SPEI leads or lags and the SCAND pattern. 

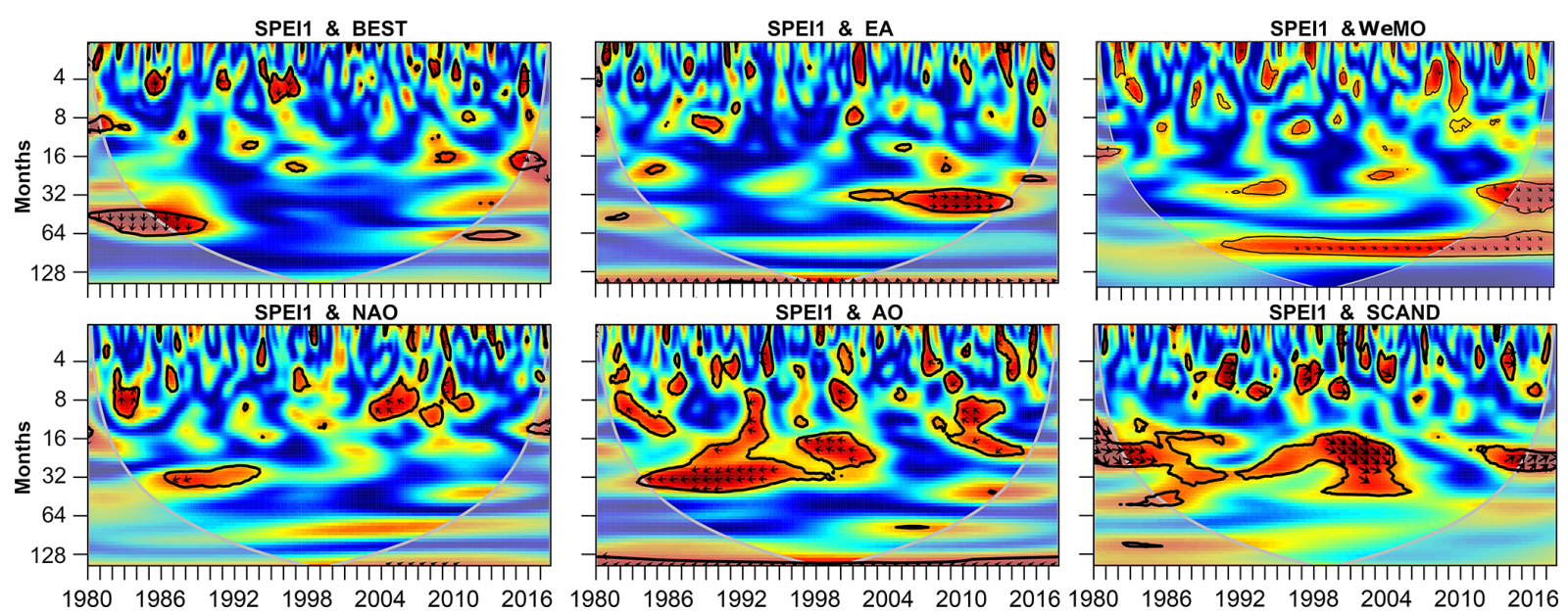

Figure 16. Wavelet coherence between the SPEI1 and the series of teleconnection patterns, namely the bivariate El Niño-Southern Oscillation time series (BEST), East Atlantic pattern (EA), North Atlantic Oscillation (NAO), Arctic Oscillation (AO), and Scandinavian pattern (SCAND). The colours from blue to red indicate the increasing coherence. Areas enclosed by a black line correspond to statistically significant cross-wavelet powers at the $95 \%$ level. The grey line depicts the cone of influence (COI), while the black arrows indicate the phase condition. The phase relationships between the climate indices and SPEI1 are denoted by arrows for the in-phase pointing right, anti-phase pointing left, climate indices leading the SPEI1 by $90^{\circ}$ pointing up, and the SPEI1 leading the climate indices by $90^{\circ}$ pointing down.

\subsection{Hydrological drought}

The temporal evolution of the SRI for temporal scales of 1 (SRI1) to 6 (SRI6) months appears in Fig. 17. Negative values of the SRI indicated runoff droughts, normally recognized as hydrological droughts. The high variability of the SRI1 makes it difficult to observe whether or not these occurred in continuous dry periods. The SRI6 better depicts the identification of continuous dry periods such as 1991-1993, 2004-2005, 2011-2012, and the end of 2006 to 2007.

In this section we present our investigation into the possible response of hydrological drought through the SRI1. This was decided considering the effect of current and previous drought conditions revealed by the SPEI1 to the SPEI24 series. Correlations values in Fig. 18a show that the SRI1 variability was well associated with the first temporal scales (1 and 2 months) of the SPEI along all of the hydrological year. However, high correlations during all SPEI temporal scales were observed for December, January, and February, thereby suggesting that surface runoff during the rainiest months may have also depended on dry and wet conditions from previous months. From April to September the highest correlations were more restricted to the previous 2-4 months. According to a statistically significant correlation in July (i.e. the climatological driest month), the surface runoff variability was also affected by dry and wet conditions from the previous 4-21 months. Moreover, the SPEI was based on a certain water balance; therefore, it would stand to reason that the runoff may vary directly with the associated $P$ annual cycle in the MLSHD. The maximum correlations in this figure indicated the best climatic timescale over which the runoff drought was measured by the SRI and responded to dry and wet conditions according to the SPEI. However, drought propagation through every component of the hydrological cycle depends on the severity of drought as well as the characteristics of the catchments (Van Lanen, 2006).

Figure $18 \mathrm{~b}$ illustrates the monthly response rate (in percentage) of hydrological drought (SRI $\leq-0.84)$ to drought at different timescales according to the SPEI1 to the SPEI24 being less than or equal to -0.84 . Dry conditions revealed at all temporal scales of the SPEI had remarkably different response rates of runoff drought across the hydrological year. The larger responses $(>50 \%)$ occurred from October to April and particularly in January, February, and March (i.e. the rainiest months). For these months, the large rate of months under hydrological drought was highly affected by drought conditions from several months before. This is in agreement with the correlation shown in Fig. 18a. From May to September the $P$ values over the MLSHD decrease, and the rate response of runoff drought reaches $\sim 20 \%$. In these months the runoff droughts are best linked to drought conditions at shorter SPEI temporal scales; as precipitation declines, the $\mathrm{Et}_{0}$ value is a determinant factor in the modulation of soil moisture content and runoff.

\section{Conclusions}

In this study drought phenomena in the MLSHD were investigated through the SPEI using high-resolution gridded datasets. An application of the EOF method revealed highly homogeneous drought features despite the complex topography of the region. During the period of the study (1980-2017), frequent meteorological droughts af- 


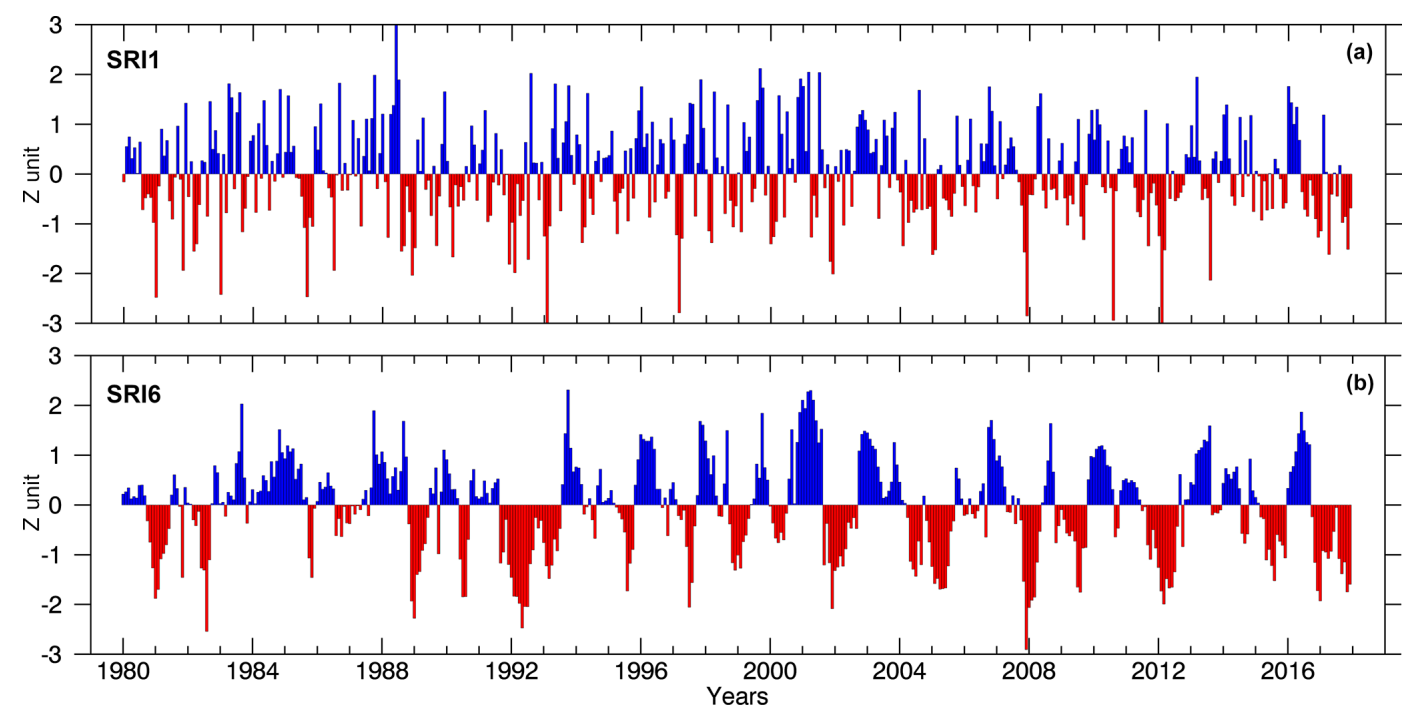

Figure 17. Temporal evolution of the standardized runoff index computed for (a) 1-month and (b) 6-month temporal scales in the MLSHD. Period of 1980-2017.

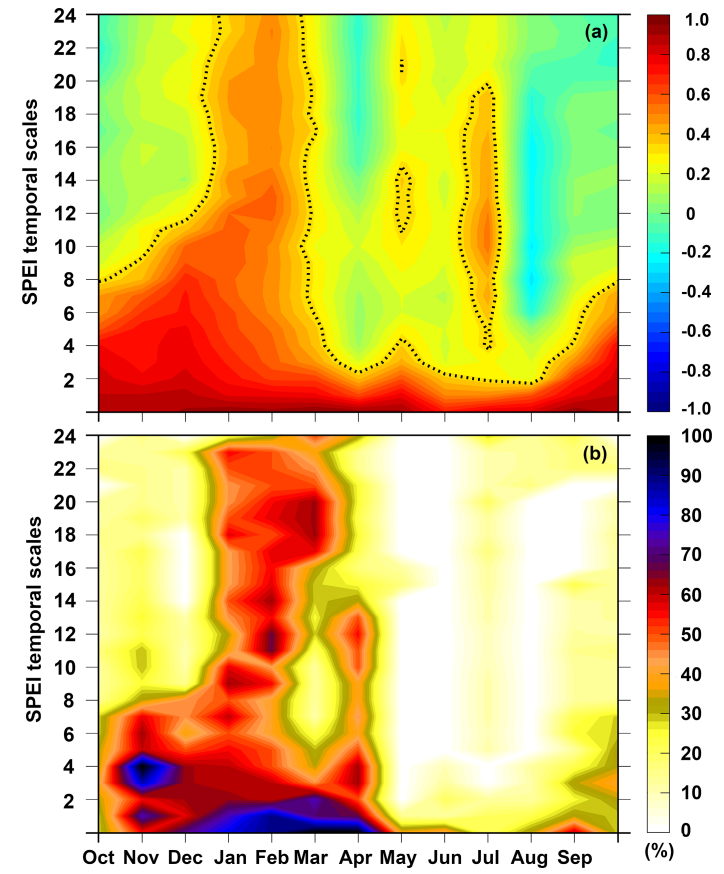

Figure 18. (a) Monthly correlations among the SRI1 for the entire Miño-Limia-Sil hydrographic demarcation (MLSHD) with the SPEI1 to the SPEI24 in the MLSHD; values within dotted lines represent significant correlations at $p<0.05$. (b) Rate (in percentage) of hydrological drought (SRI $\leq-0.84)$ during drought conditions according to the monthly SPEI $1 \leq-0.84$. Period of 1980-2017. fected the MLSHD in 1989-1992, 2004-2007, and 20152017, while the most severe drought episodes occurred during June 2016-January 2017, September 2011-March 2012, December 2014-August 2015, etc. (Table 3). To investigate the atmospheric circulation associated with different drought categories in the MLSHD, a CWT classification for the entire IP was used. The results confirm previous findings for the northwestern and entire IP, and they showed that the MLSHD is a hydroclimatic region where atmospheric circulation associated with weather types SW, W, and NW (NE, E, and SE) is related to wet (dry) conditions. A spatial correlation analysis between 10 pure CWTs and the SPEI series computed on a 1-month temporal scale revealed a highly uniform influence of every CWT (and therefore the associated circulation) on the spatial variability of dry and wet conditions.

We found that dry and wet conditions in the MLSHD were susceptible to external forcing not only in the short term but also for the mid-to-long-term changes. The most influential teleconnection patterns on the variability of dry and wet conditions in the MLSHD were the AO and SCAND pattern, followed by the NAO, which is in agreement with previous results for the region. The signals of the AO and NAO were opposite of the SPEI1 in the MLSHD, while contrastingly, the SCAND pattern was positively correlated with the SPEI1 series. Several studies have recognized the NAO as the dominant pattern for the Euro-Atlantic region. A more detailed study on the short-, medium-, and long-term impacts of the $\mathrm{NAO}$ and $\mathrm{AO}$ on the atmospheric dynamics associated with hydrometeorological extremes in the NWIP should be conducted. Similar to the SCAND pattern, the WeMOi was also positively correlated with the SPEI1 in the MLSHD. Intermittently significant coherence between the SPEI1 and other teleconnection patterns (i.e. BEST and EA) was also detected 
in the high-frequency region, but statistically significant correlations indicated there was not a strong relationship of the ENSO event and the EA mode on the water balance in the MLSHD.

The SRI was used as a complement to the SPEI for representing hydrological drought in the MLSHD. We found that a fast propagation of meteorological drought to runoff drought exists across the year; normally at very short timescales (12 months). However, this influence was higher in the climatological rainiest months of the year (winter months), when hydrological drought was affected by the previous 24 months of drought according to SPEI values less than or equal to -0.84 . This relationship was less observed in the dry season. In conclusion, this study provides information that is fundamental to understanding the climate forcing of dry conditions in the MLSHD, which is an important hydrological and socioeconomic region of the NWIP. Furthermore, these results will support hydrometeorological forecasting and water management plans for the region.

Data availability. All datasets utilized to perform this study are freely available on the internet. For further information regarding the values of drought indices, please contact the corresponding author.

Supplement. The supplement related to this article is available online at: https://doi.org/10.5194/nhess-20-1805-2020-supplement.

Author contributions. RN, MLRL, and LG conceived the idea of the study. RS, MV, MS, MLRL, and RN processed the data, analysed the results, and wrote the paper. All authors reviewed the article and provided their contributions.

Competing interests. The authors declare that they have no conflict of interest.

Special issue statement. This article is part of the special issue "Hydroclimatic extremes and impacts at catchment to regional scales". It is not associated with a conference.

Acknowledgements. Marta Vázquez and Rogert Sorí acknowledge the ability to perform research with the Universidade de Trásos-Montes e Alto Douro through the European Association for Territorial Cooperation, Galicia Northern Portugal (AECP, GNP) through the IACOBUS programme in 2018 and 2019, respectively. Rogert Sorí and Marta Vázquez acknowledge postdoctoral grants by the Xunta de Galicia (grant nos. ED481B 2019/070 and ED481B 2018/062, respectively). Margarida L. R. Liberato and Milica Stojanovic acknowledge the support received by the project "Weather Extremes in the Euro Atlantic Region: Assessment and Impacts-WEx-Atlantic" (no. PTDC/CTA-MET/29233/2017). Mar- garida L. R. Liberato acknowledges the ability to perform research with the Environmental Physics Laboratory (EPhysLab), Universidade de Vigo, Spain, through the Fundación Carolina (C.2019). All authors acknowledge the support of Alex Ramos from the Instituto Dom Luis for interpreting the CWTs computation.

Financial support. This work is part of the LAGRIMA project (grant no. RTI2018-095772-B-I00) funded by the Ministerio de Ciencia, Innovación y Universidades, Spain. Partial support was also obtained from the Xunta de Galicia under the project "Programa de Consolidación e Estructuración de Unidades de Investigación Competitivas (Grupos de Referencia Competitiva)" (no. ED431C 2017/64-GRC) and the Fundação para a Ciência e a Tecnologia and Portugal Horizon 2020 (grant no. PTDC/CTAMET/29233/2017).

Review statement. This paper was edited by Chris Reason and reviewed by two anonymous referees.

\section{References}

Abatzoglou, J., Dobrowski, S., Parks, S. A., and Hegewisch, K. C.: TerraClimate, a high-resolution global dataset of monthly climate and climatic water balance from 1958-2015, Sci. Data, 5, 170191, https://doi.org/10.1038/sdata.2017.191, 2018.

Agnew, C. T.: Using the SPI to identify drought, Drought Netw. News, 2000, 12, 6-12, available at: http://digitalcommons.unl. edu/droughtnetnews/1 (last access: 1 September 2019), 2000.

Allen, R. G., Pereira, L. S., Raes, D., and Smith, M.: Crop evapotranspiration: Guidelines for computing crop water requirements, FAO Irrigation and Drainage Paper 56, 300 pp., available at: http: //www.fao.org/3/X0490E/X0490E00.htm (last access: 1 September 2019), 1998.

Ambaum, M. H. P., Hoskins, B. J., and Stephenson, D. B.: Arctic Oscillation or North Atlantic Oscillation?, J. Climate, 14, 3495-3507, https://doi.org/10.1175/15200442(2001)014<3495:AOONAO>2.0.CO;2, 2001.

Andrade, C. and Belo-Pereira, M.: Assessment of droughts in the Iberian Peninsula using the WASP Index, Atmos. Sci. Lett., 16, 208-218, https://doi.org/10.1002/as12.542, 2015.

Añel, J. A., Bakhat, M., and Labandeira, X.: Hydrological management of a heavily dammed river basin: the Miño-Sil, working paper 03/2014, available at: http://catedranaturgy.webs4.uvigo.es/ investigacion (last access: 1 March 2020), 2014.

Barbeta, A. and Peñuelas, J.: Sequence of plant responses to droughts of different timescales: lessons from holm oak (Quercus ilex) forests, Plant. Ecol. Divers., 9, 321-338, https://doi.org/10.1080/17550874.2016.1212288, 2016.

Barnston, A. G. and Livezey, R. E.: Classification, Seasonality and Persistence of Low-Frequency Atmospheric Circulation Patterns, Mon. Weather Rev., 115, 1083-1126. https://doi.org/10.1175/15200493(1987)115<1083:CSAPOL>2.0.CO;2, 1987.

Beguería, S., Vicente-Serrano, S. M., Reig, F., and Latorre, B.: Standardized precipitation evapotranspiration index (SPEI) revisited: parameter fitting, evapotranspiration models, tools datasets 
and drought monitoring, Int. J. Climatol., 34, 3001-3023, https://doi.org/10.1002/joc.3887, 2014.

Bittelli, M., Ventura, F., Campbell, G. S., Snyder, R. L., Gallegati, F., and Pisa, P. R.: Coupling of heat, water vapor, and liquid water fluxes to compute evaporation in bare soils, J. Hydrol., 362, 191205, https://doi.org/10.1016/j.jhydrol.2008.08.014, 2008.

Bueh, C. and Nakamura, H.: Scandinavian pattern and its climatic impact, Q. J. Roy. Meteorol. Soc., 133, 2117-2131, https://doi.org/10.1002/qj.173, 2007.

CA - Convenção Albufeira: Bacia Hidrográfica do Lima: Dados Gerais, available at: http://www.cadc-albufeira.eu/pt/ cuencas-hidrograficas/cuenca-limia/, last access: 22 February 2020 .

Casanueva, A., Rodríguez-Puebla, C., Frías, M. D., and GonzálezReviriego, N.: Variability of extreme precipitation over Europe and its relationships with teleconnection patterns, Hydrol. Earth Syst. Sci., 18, 709-725, https://doi.org/10.5194/hess-18709-2014, 2014.

Coll, J., Aguilar, E., and Ashcroft, L.: Drought variability and change across the Iberian Peninsula, Theor. Appl. Climatol., 130, 901-916, https://doi.org/10.1007/s00704-016-1926-3, 2017.

Cornes, R., van der Schrier, G., van den Besselaar, E. J. M., and Jones, P. D.: An Ensemble Version of the E-OBS Temperature and Precipitation Datasets, J. Geophys. Res.-Atmos., 123, 1-52, https://doi.org/10.1029/2017JD028200, 2018.

Cortesi, N., Gonzalez-Hidalgo, J. C., Trigo, R. M., and Ramos, A. M.: Weather Types and spatial variability of precipitation in the Iberian Peninsula, Int. J. Climatol., 34, 2661-2677, https://doi.org/10.1002/joc.3866, 2014.

Dai, A.: Characteristics and trends in various forms of the Palmer Drought Severity Index during 1900-2008, J. Geophys. Res., 116, D12115, https://doi.org/10.1029/2010JD015541, 2011.

Dai, P. and Tan, B.: The Nature of the Arctic Oscillation and Diversity of the Extreme Surface Weather Anomalies It Generates, J. Climate, 30, 5563-5584, https://doi.org/10.1175/JCLI-D-160467.1, 2017.

Davarzani, H., Smits, K., Tolene, R. M., and Illangasekare, T.: Study of the effect of wind speed on evaporation from soil through integrated modeling of the atmospheric boundary layer and shallow subsurface, Water Resour. Res., 50, 661-680, https://doi.org/10.1002/2013WR013952, 2014.

deCastro, M., Lorenzo, N. G., Taboada, J. J., Sarmiento, M. E., Alvarez, I., and Gómez-Gesteira, M.: Influence of teleconnection patterns on precipitation variability and on river flow regimes in the Miño River basin (NW Iberian Peninsula), Clim. Res., 32, 63-73, https://doi.org/10.3354/cr032063, 2006a.

deCastro, M., Alvarez, I., Varela, M., Prego, R., and GómezGesteira, M.: Miño River dams discharge on neighbor Galician Rias Baixas (NW Iberian Peninsula): Hydrological, chemical and biological changes in water column, Estuarine, Coast. Shelf Sci., 70, 52-62, https://doi.org/10.1016/j.ecss.2006.05.035, 2006b.

Dee, D. P., Uppala, S. M., Simmons, A. J., Berrisford, P., Poli, P., Kobayashi, S., Andrae, U., Balmaseda, M. A., Balsamo, G., Bauer, P., Bechtold, P., Beljaars, A. C. M., van de Berg, L., Bidlot, J., Bormann, N., Delsol, C., Dragani, R., Fuentes, M., Geer, A. J., Haimberger, L., Healy, S. B., Hersbach, H., Hólm, E. V., Isaksen, L., Kållberg, P., Köhler, M., Matricardi, M., McNally, A. P., Monge-Sanz, B. M., Morcrette, J.-J., Park, B.-K., Peubey, C., de Rosnay, P., Tavolato, C., Thépaut, J.-N. and Vitart, F.: The
ERA-Interim reanalysis: Configuration and performance of the data assimilation system, Q. J. Roy. Meteorol. Soc., 137, 553597, https://doi.org/10.1002/qj.828, 2001.

Drumond, A., Nieto, R., Gimeno, L., Vicente-Serrano, S. M., and Lopez-Moreno, J. I.: Characterization of the atmospheric component of the winter hydrological cycle in the Galicia/North Portugal Euro-region: a Lagrangian approach, Clim. Res., 48, 193201, https://doi.org/10.3354/cr00987, 2011.

Eiras-Barca, J., Lorenzo, N., Taboada, J., Robles, A., and MiguezMacho, G.: On the relationship between atmospheric rivers, weather types and floods in Galicia (NW Spain), Nat. Hazards Earth Syst. Sci., 18, 1633-1645, https://doi.org/10.5194/nhess18-1633-2018, 2018.

García, N. O., Gimeno, L., de la Torre, L., Nieto, R., and Añel, J. A.: North Atlantic Oscillation (NAO) and precipitation in Galicia (Spain), Atmósfera, 18, 25-32, 2005.

García-Herrera, R., Garrido-Perez, J. M., Barriopedro, D., Ordóñez, C., Vicente-Serrano, S. M., Nieto, R., Gimeno, L., Sorí, R., and Yiou, P: The European 2016/2017 drought, J. Climate, 32, 31693187, https://doi.org/10.1175/JCLI-D-18-0331.1, 2019.

García-Herrera, R., Hernández, E., Barriopedro, D., Paredes, D., Trigo, R. M., Trigo, I. F., and Mendes, M. A.: The Outstanding 2004/05 Drought in the Iberian Peninsula: Associated Atmospheric Circulation, J. Hydrometeorol., 8, 483-498, https://doi.org/10.1175/JHM578.1, 2007.

Gómez-Gesteira, M., Gimeno, L., deCastro, M., Lorenzo, M. N., Alverez, I., Nieto, R., Taboada, J. J., Crespo, A. J. C., Ramos, A. M., Iglesias, I., Gómez-Gesteira, J. L., Sanro, F. E., Barriopedro, D., and Trigo, I. F.: The state of climate in NW Iberia, Clim. Res., 48, 109-144, https://doi.org/10.3354/cr00967, 2011.

González-Hidalgo, J. C., Vicente-Serrano, S. M., PeñaAngulo, D., Salinas, M., Tomas-Burguera, S., and Begueria, S.: High-resolution spatio-temporal analyses of drought episodes in the western Mediterranean basin (Spanish mainland, Iberian Peninsula), Acta Geophys., 66, 381-392, https://doi.org/10.1007/s11600-018-0138-x, 2018.

Gouveia, C., Trigo, R. M., and DaCamara, C. C.: Drought and vegetation stress monitoring in Portugal using satellite data, Nat. Hazards Earth Syst. Sci., 9, 185-195, https://doi.org/10.5194/nhess9-185-2009, 2009.

Grinsted, A., Moore, J. C., and Jevrejeva, S.: Application of the cross wavelet transform and wavelet coherence to geophysical time series, Nonlin. Processes Geophys., 11, 561-566, https://doi.org/10.5194/npg-11-561-2004, 2004.

Gu, L., Chen, J., Yin, J., Xu, C.-Y., and Chen, H.: Drought hazard transferability from meteorological to hydrological propagation, J. Hydrol., 585, 124761, https://doi.org/10.1016/j.jhydrol.2020.124761, 2020.

Guerreiro, S. B., Dawson, R. J., Kilsby, C., Lewis, E., and Ford, A.: Future heat-waves,droughts and floods in 571 European cities, Environ. Res. Lett., 13, 1-11, https://doi.org/10.1088/17489326/aaaad3, 2018.

Hanna, E., Cropper, T. E., Jones, P. D., Scaife, A. A. and Allan, R.: Recent seasonal asymmetric changes in the NAO (a marked summer decline and increased winter variability) and associated changes in the $\mathrm{AO}$ and Greenland Blocking Index, Int. J. Climatol., 35, 2540-2554, https://doi.org/10.1002/joc.4157, 2015. 
Hargreaves, G. H. and Samani, Z.: Reference crop evapotranspiration from temperature, Appl. Eng. Agric., 1, 96-99, https://doi.org/10.13031/2013.26773, 1985.

Hénin, R., Ramos, A. M., Schemm, S., Gouveia, C. M., and Liberato, M. L. R.: Assigning precipitation to mid-latitudes fronts on sub-daily scales in the North Atlantic and European sector: Climatology and trends, Int. J. Climatol., 39, 317-330, https://doi.org/10.1002/joc.5808, 2019.

Herrera, S., Cardoso, R. M., Soares, P. M., Espírito-Santo, F., Viterbo, P., and Gutiérrez, J. M.: Iberia01: a new gridded dataset of daily precipitation and temperatures over Iberia, Earth Syst. Sci. Data, 11, 1947-1956, https://doi.org/10.5194/essd-11-19472019, 2019.

Hofstra, N., Haylock, M., New, M., and Jones, P. D.: Testing EOBS European high-resolution gridded data set of daily precipitation and surface temperature, J. Geophys. Res., 144, D21101, https://doi.org/10.1029/2009JD011799, 2009.

Hofstra, N., New, M., and McSweeney, C.: The influence of interpolation and station network density on the distributions andtrends of climate variables in gridded daily data, Clim. Dynam., 35, 841-858, https://doi.org/10.1007/s00382-009-0698-1, 2010.

Hurrell, J. W.: Decadal trends in the North Atlantic Oscillation and relationships to regional temperature and precipitation, Science, 269, 676-679, https://doi.org/10.1126/science.269.5224.676, 1995.

Hurrell, J. W., Kushnir, Y., Ottersen, G., and Visbeck, M.: An overview of the North Atlantic Oscillation, Geophys. Monogr. Ser., 134, 1-35, https://doi.org/10.1029/134GM01, 2003.

IPCC: Summary for Policymakers, in: Global Warming of $1.5^{\circ} \mathrm{C}$, in: An IPCC Special Report on the impacts of global warming of $1.5^{\circ} \mathrm{C}$ above pre-industrial levels and related global greenhouse gas emission pathways, in the context of strengthening the global response to the threat of climate change, sustainable development, and efforts to eradicate poverty, edited by: MassonDelmotte, V., Zhai, P., Pörtner, H.-O., Roberts, D., Skea, J., Shukla, P. R., Pirani, A., Moufouma-Okia, W., Péan, C., Pidcock, R., Connors, S., Matthews, J. B. R., Chen, Y., Zhou, X., Gomis, M. I., Lonnoy, E., Maycock, T., Tignor, M., and Waterfield, T., World Meteorological Organization, Geneva, Switzerland, 32 pp., 2018.

Jenkinson, A. F. and Collison, F. P.: An Initial Climatology of Gales over the North Sea, Synoptic Climatology Branch Memorandum No. 62, Meteorological Office, Bracknell, 1977.

Jones, P. D., Hulme, M., and Briffa, K. R.: A comparison of Lamb circulation types with an objective classification scheme, Internat. J. Climatol., 18, 655-663, https://doi.org/10.1002/joc.3370130606, 1993.

Jones, P. D., Jonsson, T., and Wheeler, D. A.: Monthly values of the North Atlantic Oscillation Index from 1821 to 2000, PANGAEA, https://doi.org/10.1594/PANGAEA.56559, 1997.

Kendall, M. G.: Rank Correlation Methods, 4th Edn., Charles Griffin, London, 1975.

Knapp, A. K., Carroll, C. J. W., Denton, E. M., La Pierre, K. J., Collins, S. L., and Smith, M. D.: Differential sensitivity to regional-scale drought in six central US grasslands, Oecologia, 177, 949-957, https://doi.org/10.1007/s00442-015-3233-6, 2015.
Lana, X., Martínez, M. D., Burgueño, A., Serra, C., Martín-Vide, J., and Gómez, L.: Distributions of long dry spells in the iberian peninsula, years 1951-1990, Int. J. Climatol., 26, 1999-2021, https://doi.org/10.1002/joc.1354, 2006.

Lehner, B., Verdin, K., and Jarvis, A.: New global hydrography de-rived from spaceborne elevation data, Eos Trans. ,89, 93-94, https://doi.org/10.1029/2008EO100001, 2011.

Liberato, M. L. R., Ramos, A. M., Gouveia, C. M., Sousa, P., Russo, A., Trigo, R. M., and Santo, F. E.: Exceptionally extreme drought in Madeira Archipelago in 2012: Vegetation impacts and driving conditions, Agr. Forest Meteorol., 232, 195209, https://doi.org/10.1016/j.agrformet.2016.08.010, 2017.

Lloyd-Hughes, B. and Saunders, M. A.: A drought climatology for Europe, Int. J. Climatol., 22, 1571-1592, https://doi.org/10.1002/joc.846, 2002.

López-Moreno, J. I., Hess, T. M., and White, A. S. M.: Estimation of reference evapotranspiration in a mountainous mediterranean site using the Penman-Monteith equation with limited meteorological data, Pirineos JACA, 164, 7-31, https://doi.org/10.3989/pirineos.2009.v164.27, 2009.

Lorenzo, M. N., Taboada, J. J., and Gimeno, L.: Links between circulation weather types and teleconnection patterns and their influence on precipitation patterns in Galicia (NW Spain), Int. J. Climatol., 28, 1493-1505, https://doi.org/10.1002/joc.1646, 2008.

Lorenzo, M. N., Taboada, J. J., Iglesias, I., and Gómez-Gesteira, M.: Predictability of the spring rainfall in Northwestern Iberian Peninsula from sea surfaces temperature of ENSO areas, Climatic Change, 107, 329-341, https://doi.org/10.1007/s10584010-9991-6, 2010.

Lorenzo-Lacruz, J., Morán-Tejeda, E., Vicente-Serrano, S. M., and López-Moreno, J. I.: Streamflow droughts in the Iberian Peninsula between 1945 and 2005: spatial and temporal patterns, Hydrol. Earth Syst. Sci., 17, 119-134, https://doi.org/10.5194/hess17-119-2013, 2013.

Mann, H. B.: Non-parametric tests against trend, Econometrica 13, 163-171, 1945.

Manning, C., Widmann, M., Bevacqua, E., Van Loon, A. F., Maraun, D., and Vrac, M.: Increased probability of compound long-duration dry and hot events in Europe during summer (1950-2013), Environ. Res. Lett., 14, 094006, https://doi.org/10.1088/1748-9326/ab23bf, 2019.

Manzano, A. M., Clemente, M. A., Morata, A., Luna, M. Y., Beguería, S., Vicente-Serrano, S. M., and Martín, M. L.: Analysis of the atmospheric circulation pattern effects over SPEI drought index in Spain, Atmos. Res., 230, 104630, https://doi.org/10.1016/j.atmosres.2019.104630, 2019.

Martín-Vide, J. and Lopez-Bustins, J. A.: The Western Mediterranean Oscillation and rainfall in the Iberian Peninsula, Int J. Climatol., 26, 1455-1475, https://doi.org/10.1002/joc.1388, 2006.

Martin-Vide, J., Sanchez-Lorenzo, A., Lopez-Bustins, J. A., Cordobilla, M. J., Garcia-Manuel, A., and Raso, J. M.: Torrential rainfall in northeast of the Iberian Peninsula: synoptic patterns and WeMO influence, Adv. Sci. Res., 2, 99-105, https://doi.org/10.5194/asr-2-99-2008, 2008.

McKee, T. B. N., Doesken, J., and Kleist, J.: The relationship of drought frequency and duration to time scales, in: Eight 
Conf. On Applied Climatology, Anaheim, California, USA, 179184, 1993.

McMichael, A. J. and Lindgren, E.: Climate change: present and future risks to health, and necessary responses, J. Intern. Med., 270, 401-413, https://doi.org/10.1111/j.13652796.2011.02415.x, 2011.

Miralles, D. G., Gentine, P., Seneviratne, S. I., and Teuling, A. J.: Land-atmospheric feedbacks during droughts and heatwaves: state of the science and current challenges, Ann. NY Acad. Sci., 1436, 19-35, https://doi.org/10.1111/nyas.13912, 2019.

Monish, N. T. and Rehana, S.: Suitability of distributions for standard precipitation and evapotranspiration index over meteorologically homogeneous zones of India, J. Earth Syst. Sci., 129, 25, https://doi.org/10.1007/s12040-019-1271-x, 2020.

Mora Aliseda, J., Garrido Velarde, J., and Díaz González, M.: Dinámicas socio-espaciales y previsiones demográficas en la cuenca internacional del Miño-Sil, Anales De Geografía De La Universidad Complutense, 35, 95-117, https://doi.org/10.5209/rev_AGUC.2015.v35.n1.48965, 2015.

Muñoz-Díaz, D. and Rodrigo, F. S.: Influence of the El NiñoSouthern Oscillation on the probability of dry and wet seasons in Spain, Clim. Res., 30, 1-12, https://doi.org/10.3354/cr030001, 2004.

Ojeda, M. G.-V., Jiménez, E. R., Gámiz-Fortis, S. R., Castro-Díez, Y., and Esteban Parra, M. J.: Understanding the Drought Phenomenon in the Iberian Peninsula, in: book: Drought (Aridity), Intechopen, London, UK, 1-18, https://doi.org/10.5772/intechopen.85472, 2019.

Paredes, D., Trigo, R. M., Garcia-Herrera, R., and Trigo, I. F.: Understanding Precipitation Changes in Iberia in Early Spring: Weather Typing and Storm-Tracking Approaches, J. Hydrometeorol., 7, 101-113, https://doi.org/10.1175/JHM472.1, 2006.

Parracho, A. C., Gonçalves, P. M., and Rocha, A.: Regionalisation of precipitation for the Iberian Peninsula and climate change, Phys. Chem. Earth, 54, 146-154, https://doi.org/10.1016/j.pce.2015.07.004, 2016.

Páscoa, P., Gouveia, C. M., Russo, A., and Trigo, R. M.: Drought Trends in the Iberian Peninsula over the Last 112 Years, Adv. Meteorol., 2017, 4653126, https://doi.org/10.1155/2017/4653126, 2017.

Patakamuri, S. K. and O'Brien, N.: Modified Versions of Mann Kendall and Spearman's Rho Trend Tests version 1.4.0, available at: https://cran.r-project.org/web/packages/modifiedmk/ modifiedmk.pdf, last access: 10 September 2019.

Peña-Gallardo, M., Vicente-Serrano, S. M., Domínguez-Castro, F., and Beguería, S.: The impact of drought on the productivity of two rainfed crops in Spain, Nat. Hazards Earth Syst. Sci., 19, 1215-1234, https://doi.org/10.5194/nhess-19-1215-2019, 2019.

PES - Plan especial de actuación en situaciones de alerta y eventual sequía: Documento Ambiental Estratégico, Confederación Hidrográfica del Miño-Sil, available at: https://www.chminosil. es (last access: 10 February 2020), 2017.

PH - Plan Hidrológico de la parte española de la Demarcación Hidrográfica del Miño-Sil (2015-2021): Capítulo 3, $127-$ 128 pp., 2014, available at: https://www.chminosil.es. (last access: 10 February 2020), 2014.

Potop, V., Boroneant, C., Možný, M., Štěpánek, P., and Skalák, P.: Observed spatiotemporal characteristics of drought on various time scales over the Czech Republic, Theor. Appl. Clima- tol., 115, 563-581, https://doi.org/10.1007/s00704-013-0908-y, 2013.

Preisendorfer, R. W. and Mobley, C. D.: Principal component analysis in meteorology and oceanography, Elsevier, Amsterdam, 425 pp., 1988.

Ramos, A. M., Cortesi, N., and Trigo, R. M.: Circulation weather types and spatial variability of daily precipitation in the Iberian Peninsula, Front. Earth Sci., 2, 1-17, https://doi.org/10.3389/feart.2014.00025, 2014.

Rivière, G. and Drouard, M.: Dynamics of the Northern Annular Mode at Weekly Time Scales, J. Atmos. Sci., 72, 4569-4590, https://doi.org/10.1175/JAS-D-15-0069.1, 2015.

Rodríguez-Puebla, C., Encinas, A. H., Nieto, S., and Garmendia, J.: Spatial and temporal patterns of annual precipitation variability over the Iberian Peninsula, Int. J. Climatol., 18, 299-316, https://doi.org/10.1002/(SICI)10970088(19980315)18:3<299::AID-JOC247>3.0.CO;2-L, 1998.

Rodríguez-Puebla, C. and Nieto, S.: Trends of precipitation over the Iberian Peninsula and the North Atlantic Oscillation under climate change conditions, Int. J. Climatol., 30, 1807-1815, https://doi.org/10.1002/joc.2035, 2010.

Rogers, J. and McHugh, M.: On the separability of the North Atlantic oscillation and Arctic oscillation, Clim. Dynam., 19, 599608, https://doi.org/10.1007/s00382-002-0247-7, 2002.

Russo, C., Gouveia, M., Trigo, R. M., Liberato, M. L., and DaCamara, C. C.: The influence of circulation weather patterns at different spatial scales on drought variability in the Iberian Peninsula, Front. Environ. Sci., 3, 1-15, https://doi.org/10.3389/fenvs.2015.00001, 2015.

Sáez de Cámara, E., Gangoiti, G., Alonso, L., and Iza, J.: Daily precipitation in Northern Iberia: Understanding the recent changes after the circulation variability in the North Atlantic sector, J. Geophys. Res.-Atmos., 120, 9981-9910, https://doi.org/10.1002/2015JD023306, 2015.

Salah, Z., Nieto, R., Drumond, A., Gimeno, L., and Vicente-Serrano, S. M.: A Lagrangian analysis of the moisture budget over the Fertile Crescent during two intense drought episodes, J. Hydrol., 560, 382-395, https://doi.org/10.1016/j.jhydrol.2018.03.021, 2018.

Salvador, C., Nieto, R., Linares, C., Díaz, J., and Gimeno, L.: Effects on daily mortality of droughts in Galicia (NW Spain) from 1983 to 2013, Sci. Total Environ., 662, 121-133, https://doi.org/10.1016/j.scitotenv.2019.01.217, 2019.

Schulte, E. M., Grilo, C. M., and Gearhardt, A. N.: Shared and unique mechanisms underlying binge eating disorder and addictive disorders, Clin. Psychol. Rev., 44, 125-139, https://doi.org/10.1016/j.cpr.2016.02.001, 2016.

Sen, P. K.: Estimates of Regression Coefficient Based on Kendall's tau, J. Am. Stat. Assoc., 63, 1379-1389, 1968.

Seneviratne, S.: Historical drought trends revisited, Nature, 491, 338-339, https://doi.org/10.1038/491338a, 2012.

Serrano, A., García, J. A., Mateus, V. L., Cancillo, M. L., and Garrido, J.: Monthly modes of variation of precipitation over the Iberian Peninsula, J. Climate, 12, 2894-2919, https://doi.org/10.1175/15200442(1999)012<2894:MMOVOP>2.0.CO;2, 1999.

Smith, C. A. and Sardeshmukh, P.: The Effect of ENSO on the Intraseasonal Variance of Surface Temperature in Winter, 
Int. J. Climatol., 20, 1543-1557, https://doi.org/10.1002/10970088(20001115)20:13<1543::AID-JOC579>3.0.CO;2-A, 2000.

Sordo-Ward, A., Dolores Bejarano, M., Iglesias, A., Asenjo, V., and Garrote, L.: Analysis of Current and Future SPEI Droughts in the La Plata Basin Based on Results from the Regional Eta Climate Model, Water, 9, 857, https://doi.org/10.3390/w9110857, 2017.

Sousa, P. M., Barriopedro, D., Trigo, R. M., Ramos, A. M., Nieto, R., Gimeno, L., Turkman, K. F., and Liberato, M. L. R.: Impact of Euro-Atlantic blocking patterns in Iberia precipitation using a novel high resolution dataset, Clim. Dynam., 46, 2573-2591, https://doi.org/10.1007/s00382-015-2718-7, 2016.

Spinoni, J., Naumann, G., Vogt, J., and Barbosa, P.: Meteorological droughts in Europe, Events and impacts, past trends and future projections, Publications Office of the European Union, Luxembourg, EUR 27748 EN, 129 pp., https://doi.org/10.2788/450449, 2016.

Spinoni, J., Naumann, G., and Vogt, J. V.: Pan-European seasonal trends and recent changes of drought frequency and severity, Global Planet. Change, 148, 113-130, https://doi.org/10.1016/j.gloplacha.2016.11.013, 2017.

Spinoni, J., Vogt, J. V., Naumann, G., Barbosa, P., and Dosio, A.: Will drought events become more frequent and severe in Europe?, Int. J. Climatol., 38, 1718-1736, https://doi.org/10.1002/joc.5291, 2018.

Stanke, C., Kerac, M., Prudhomme, C., Medlock, J., and Murray, V.: Health effects of drought: a systematic review of the evidence, PLoS Curr., 5, 1-22, 2013.

Sunyer, M. A., Sørup, H. J. D., Christensen, O. B., Madsen, H., Rosbjerg, D., Mikkelsen, P. S., and ArnbjergNielsen, K.: On the importance of observational data properties when assessing regional climate model performance of extreme precipitation, Hydrol. Earth Syst. Sci., 17, 4323-4337, https://doi.org/10.5194/hess-17-4323-2013, 2013.

Svoboda, M., Fuchs, B.: Handbook of Drought Indicators and Indices, World Meteorological Organization (WMO) and Global Water Partnership (GWP), Geneva, Switzerland, 1-45, 2016.

Tabari, H. and Willems, P.: Lagged influence of Atlantic and Pacific climate patterns on European extreme precipitation, Sci. Rep.-UK, 8, 5748, https://doi.org/10.1038/s41598-018-24069-9, 2018.

Thompson, D. W. J. and Wallace, J. M.: The Arctic Oscillation signature in the wintertime geopotential height and temperature fields, Geophys. Res. Lett., 25, 1297-1300, https://doi.org/10.1029/98GL00950, 1998.

Tomas-Burguera, M., Vicente-Serrano, S. M., Grimalt, M., Begueria, S.: Accuracy of reference evapotranspiration $\left(\mathrm{ET}_{0}\right)$ estimates under data scarcity scenarios in the Iberian Peninsula, Agr. Water Manage., 182, 103-116, https://doi.org/10.1016/j.agwat.2016.12.013, 2017.

Torrence, C. and Compo, P.: A practical guide to wavelet analysis, B. Am. Meteorol. Soc., 79, 61-78, 1998.

Torrence, C. and Webster, P. J.: Interdecadal Changes in the ENSO-Monsoon System, J. Climate, 12, 2679-2690, https://doi.org/10.1175/15200442(1999)012<2679:ICITEM>2.0.CO;2, 1999.

Trenberth, K. E., Dai, A., Schrier, G., Jones, P. D., Barichivich, J., Briffa, K. R. and Sheffield, J.: Global warming and changes in drought, Nat. Clim. Change, 4, 17-22, https://doi.org/10.1038/nclimate2067, 2014.
Trigo, R. M. and DaCamara, C. C.: Circulation weather types and their influence on the precipitation regime in Portugal, Int. J. Climatol., 20, 1559-1581, https://doi.org/10.1002/10970088(20001115)20:13<1559::AID-JOC555>3.0.CO;2-5, 2000.

Trigo, R. M., Osborn, T. J., and Corte-Real, J.: The North Atlantic Oscillation influence on Europe: Climate impacts and associated physical mechanisms, Clim., Res., 20, 9-17, https://doi.org/10.3354/cr020009, 2002.

Trigo, R. M., Pozo-Vázquez, D., Osborn, T. J., Castro-Díez, Y., Gámiz-Fortis, S., and Esteban-Parra, M. J.: North Atlantic oscillation influence on precipitation, river flow and water resources in the Iberian Peninsula, Int. J. Climatol., 24, 925-944, https://doi.org/10.1002/joc.1048, 2004.

Trigo, R. M., Añel, J. A., Barriopedro, D., Garcia-Herrera, R., Gimeno, L., Nieto, R., Castillo, R., Allen, M. R., and Massey, N.: The record winter drought of 2011-2012 in the Iberian Peninsula, B. Am. Meteorol. Soc., 94, 41-45, 2013.

UN: Drainage basins of the North Sea and Eastern Atlantic, Chapter 7, in: Second Assessment of Transboundary Rivers, Lakes and Groundwaters, UN, New York, 182-215, https://doi.org/10.18356/57863ad2-en, 2011.

Van Lanen, H. A. J.: Drought propagation through the hydrological cycle. Climate Variability and Change - Hydrological Impacts, in: Proceedings of the Fifth FRIEND World Conference, November 2006, Havana, Cuba, 122-127, 2006.

Van Loon, A. F., Stahl, K., Di Baldassarre, G., Clark, J., Rangecroft, S., Wanders, N., Gleeson, T., Van Dijk, A. I. J. M., Tallaksen, L. M., Hannaford, J., Uijlenhoet, R., Teuling, A. J., Hannah, D. M., Sheffield, J., Svoboda, M., Verbeiren, B., Wagener, T., and Van Lanen, H. A. J.: Drought in a humanmodified world: reframing drought definitions, understanding, and analysis approaches, Hydrol. Earth Syst. Sci., 20, 36313650, https://doi.org/10.5194/hess-20-3631-2016, 2016.

Vargas, J. and Paneque, P.: Challenges for the Integration of Water Resource and Drought-Risk Management in Spain, Sustainability, 11, 1-16, https://doi.org/10.3390/su11020308, 2019.

Vicente-Serrano, S. M.: El Niño and La Niña influence on droughts at different timescales in the Iberian Peninsula, Water Resour Res., 41, 1-18, https://doi.org/10.1029/2004WR003908, 2005.

Vicente-Serrano, S. M.: Evaluating the Impact of Drought Using Remote Sensing in a Mediterranean, Semi-arid Region, Nat. Hazards, 40, 173-208, https://doi.org/10.1007/s11069-0060009-7, 2007.

Vicente-Serrano, S. M. and Beguería S.: Comment on 'Candidate distributions for climatological drought indices (SPI and SPEI)' by James H. Stagge et al., Int. J. Climatol., 36, 2120-2131, 2016.

Vicente-Serrano, S. M., Beguería, S., and López-Moreno, J. I.: A Multiscalar Drought Index Sensitive to Global Warming: The Standardized Precipitation Evapotranspiration Index, J. Climate, 23, 1696-1718, https://doi.org/10.1175/2009JCLI2909.1, 2010.

Vicente-Serrano, S. M., López-Moreno, J. I., Drumond, A., Gimeno, L., Nieto, R., Morán-Tejeda, E., LorenzoLacruz, J., Begueria, S., and Zabalza, J.: Effects of warming processes on droughts and water resources in the NW Iberian-Peninsula (1930-2006), Clim. Res., 48, $203-$ 212, https://doi.org/10.3354/cr01002, 2011.

Vicente-Serrano, S. M., López-Moreno, J. I., Santiago, B., LorenzoLacruz, J., Azorin-Molina, C., and Morán-Tejeda, E.: Accurate computation of a streamflow drought index, J. Hydrol. 
Eng., 17, 318-332, https://doi.org/10.1061/(ASCE)HE.19435584.0000433, 2012.

Vicente-Serrano, S. M., López-Moreno, J. I., Bergueria, S., Lorenzo-Lacruz, J., Sanchez-Lorenzo, A., García-Ruiz, J. M., Azorin-Molina, Morán-Tejeda, E., Revuelto, J., and Trigo, R.: Evidence of increasing drought severity caused by temperature rise in southern Europe, Environ. Res. Lett., 9, 1-14, https://doi.org/10.1088/1748-9326/9/4/044001, 2014.

Vicente-Serrano, S. M., Aguilar, E., Martínez, R., MartínHernández, N., AzorinMolina, C., Sanchez-Lorenzo, A., El Kenawy, A., Tomás-Burguera, M., Moran-Tejeda, E., LópezMoreno, J. I., Revuelto, J., Beguería, S., Nieto, J. J., Drumond, A., Gimeno, L. and Nieto, R.: The Complex influence of ENSO on droughts in Ecuador, Clim. Dynam., 48, 405-427, https://doi.org/10.1007/s00382-016-3082-y, 2016.

Vidal-Macua, J. J., Ninyerola, M., Zabala, A., Domingo-Marimon, C., and Pons, X.: Factors affecting forest dynamics in the Iberian Peninsula from 1987 to 2012. The role of topography and drought, Forest Ecol. Manage., 406, 290-306, https://doi.org/10.1016/j.foreco.2017.10.011, 2017.

Visbeck, M. H., Hurrell, J. W., Polvani, L., and Cullen, H. M.: The North Atlantic Oscillation: Past, present, and future, P. Natl. Acad. Sci. USA, 98, 12876-12877, https://doi.org/10.1073/pnas.231391598, 2001.

von Storch, V. H.: Misuses of statistical analysis in climate research, in: Analysis of Climate Variability: Applications of Statistical Techniques, edited by: von Storch, H. V. and Navarra, A., Springer Verlag, Berlin, 11-26, 1995.

Wang, H., Pan, Y., and Chen, Y.: Comparison of three drought indices and their evolutionary characteristics in the arid region of northwestern China, Atmos. Sci. Lett, 18, 132-139, https://doi.org/10.1002/as1.735, 2017.

Wang, R., Peng, W., Liu, X., Wu, W., Chen, X., and Zhang, S.: Responses of Water Level in China's Largest Freshwater Lake to the Meteorological Drought Index (SPEI) in the Past Five Decades, Water, 10, 137, https://doi.org/10.3390/w10020137, 2018.
Wang, W., Ertsen, M. W., Svoboda, M. D., and Hafeez, M.: Propagation of Drought: From Meteorological Drought to Agricultural and Hydrological Drought, Adv. Meteorol., 2016, 6547209, https://doi.org/10.1155/2016/6547209, 2016.

Wang, Y., Quan, Q., and Shen B.: Spatio-temporal variability of drought and effect of large scale climate in the source region of Yellow River, Geomat. Nat. Hazards Risk, 10, 678-698, https://doi.org/10.1080/19475705.2018.1541827, 2019.

Wanner, H., Brönnimann, S., Casty, C., Gyalistras, D., Luterbacher, J., Schmutz, C., Stephenson, D. B., and Xoplaki, E.: North Atlantic Oscillation - Concepts and Studies, Surv. Geophys., 22, 321-381, https://doi.org/10.1023/A:1014217317898, 2001.

Wehrli, K., Guillod, B. P., Hauser, M., Leclair, M., and Seneviratne, S. I.: Assessing the dynamic versus thermodynamic origin of climate model biases, Geophys. Res. Lett., 45, 8471-8479, https://doi.org/10.1029/2018GL079220, 2018.

Wilhite, D. A.: Drought as a Natural Hazard: Concepts and Definitions, in: Drought: A Global Assessment, Natural Hazards and Disasters Series, edited by: Wilhite, D. A., Routledge, London, UK, 3-18, 2000.

WMO - World Meteorological Organization: Standardized Precipitation Index User Guide, available at: http://www.wamis. org/agm/pubs/SPI/WMO_1090_EN.pdf (last access: 8 September 2019), 2012.

WMO and GWP - World Meteorological Organization and Global Water Partnership: Handbook of Drought Indicators and Indices, in: Integrated Drought Management Programme (IDMP), Integrated Drought Management Tools and Guidelines Series 2, edited by: Svoboda, M. and Fuchs, B. A., Geneva, 2016.

WMO and GWP - World Meteorological Organization and Global Water Partnership: Benefits of action and costs of inaction: Drought mitigation and preparedness - a literature review, in: Integrated Drought Management Programme (IDMP), Working Paper 1, edited by: Gerber, N. and Mirzabaev, A., WMO, Geneva, Switzerland and GWP, Stockholm, Sweden, 2017. 